\title{
El análisis estilístico de la cerámica para evaluar cambios y transformaciones sociales: Un ejemplo de la alfarería tardía local del sector centro-sur de Quebrada de Humahuaca (Jujuy, Argentina)
}

Agustina Scaro*

\section{Resumen}

En la presente contribución se aborda el estudio de una muestra de alfarería tardía (períodos Tardío e Incaico) del sector centro-sur de Quebrada de Humahuaca, considerando que su análisis brinda información acerca de conductas humanas y prácticas sociales vinculadas con su producción, distribución y consumo, tanto en actividades cotidianas como en aquellas de índole ritual. Se expone el repertorio morfológicodecorativo elaborado a partir del análisis de formas y decoraciones presentes en la alfarería local de estos momentos, buscando establecer continuidades y cambios ocurridos en ella entre el período Tardío y la dominación incaica. Con el fin de considerar posibles identidades sociales locales puestas en juego en la materialidad y las redes de interacción, se compara el material analizado del sector centro-sur del período Tardío con la cerámica de sitios más septentrionales de la Quebrada. El análisis estilístico propuesto permitió establecer los atributos de la alfarería utilizados para expresar y negociar una identidad particular durante el período Tardío, así como proponer cambios y continuidades a nivel de forma y decoración en la cerámica local a partir de la anexión de la zona al incario.

Pottery stylistic analysis as a means of evaluating change and social transformation: A late local pottery case-study from the centersouth sector of Quebrada de Humahuaca (Jujuy, Argentina)
Recibido: 7 de marzo de 2018

Aceptado:

6 de agosto de 2018

\section{Palabras clave}

Alfarería

Análisis estilístico

Períodos Tardío e Incaico

Prácticas sociales

Quebrada de Humahuaca

Sector centro-sur

\begin{abstract}
This article addresses the study of a late pottery (Late and Inca periods) assemblage from the center-south sector of Quebrada de Humahuaca. This analysis provides data concerning human behavior and social practices linked to pottery production, distribution and consumption, both in daily and ritual activities. We present the decorative-morphological repertoire, generated from the analysis of forms and decorations of the local pottery of this period, in order to establish the continuities and
\end{abstract}

Keywords

Pottery

Stylistic analysis

Late and Inca periods

Social practices

Quebrada de Humahuaca

Central-south sector 
changes in ceramics between the Late Period and Inca domination. In order to assess possible local social identities displayed through the ceramic's materiality and through interaction networks, the Late Period analyzed material from the center-south sector was compared with the ceramic of sites situated along the central and northern sector of Quebrada de Humahuaca. The stylistic analysis undertaken allowed us to establish the characteristics of the pottery used to express and negotiate a particular identity during the Late Period. It also allowed us to trace changes and continuities in form and decoration in local ceramics following the annexation of the area by the Inca Empire.

\section{Introducción}

La cerámica, en tanto una de las labores productivas más generalizadas del pasado (Skibo y Feinman, 1999), permite acceder a distintos aspectos de la vida de la gente. Así, el estudio de recipientes cerámicos, lejos de ser un fin en sí mismo, es un instrumento que sirve para responder a diversos interrogantes arqueológicos. A través del análisis estilístico de las vasijas pueden explorarse cambios, continuidades y transiciones de las estructuras sociales en el tiempo, así como procesos de interacción social a corta y larga distancia y de identidad de los grupos que las produjeron y utilizaron (Bugliani, 2008). A su vez, la alfarería jugó un rol esencial en la construcción del paisaje de las sociedades del pasado, en tanto habría brindado una experiencia del mundo más allá de lo local, ya que habría circulado a través de distintos espacios y participado en diversas transacciones y contextos de uso (Lazzari, 2005).

Partiendo desde esta perspectiva, en este trabajo se presenta el análisis de los elementos morfo-iconográficos de la cerámica tardía local (período Tardío e Incaico) del sector centro-sur de Quebrada de Humahuaca, con el fin de avanzar en la comprensión de las identidades sociales locales y las redes de interacción en las que habrían participado las sociedades del pasado. Asimismo, se busca establecer estados de atributos que puedan ser utilizados como marcadores cronológicos, permitiendo diferenciar la alfarería de momentos incaicos de aquella del período Tardío (en adelante PT). El estudio propuesto pone en relevancia la importancia de un análisis estilístico detallado, contribuyendo a la comprensión del rol que jugaron las vasijas en la vida cotidiana de las sociedades del pasado.

\section{Los momentos prehispánicos tardíos en Quebrada de Humahuaca}

La Quebrada de Humahuaca presenta una larga ocupación, con más de diez mil años de presencia humana. A continuación caracterizaremos la misma centrándonos en los últimos momentos de su historia prehispánica, entre los siglos XIII y XVI.

\section{El período Tardío}

Diversos autores (González y Pérez, 1966; Núñez Regueiro, 1974; Tarragó, 2000, entre otros) han coincidido en señalar que hacia el siglo X se observaron cambios en las sociedades prehispánicas de los Andes Centro-Sur. Los mismos habrían estado vinculados con nuevos procesos demográficos, políticos y económicos dados por la intensificación en el manejo de recursos naturales por medio de la irrigación, la explotación ganadera intensiva y el control de diversos pisos ecológicos en el marco de un creciente conflicto entre las poblaciones. Las mencionadas transformaciones y en particular el conflicto en el Noroeste Argentino (en adelante NOA) y en los Andes Centro-Sur fueron explicados de diversas formas por los investigadores, quienes 
consideraron el crecimiento demográfico (Madrazo y Ottonello, 1966), el colapso de las sociedades que concentraban el poder económico y político en Tiwanaku (Ruiz y Albeck, 1997; Tarragó, 2000) o los procesos de aridización en la región (Nielsen, 2001) como posibles causas.

En el ámbito de Quebrada de Humahuaca, se han hallado evidencias de un sistema agrícola-ganadero bien implementado mediante tecnologías que permitieron ampliar y mejorar los campos de cultivos y la rotación de pastizales. El aumento demográfico de la época, evidenciado por el creciente tamaño de los sitios y por la concentración de la población, llevaron al surgimiento de grandes poblados conglomerados ubicados principalmente en lugares altos y de difícil acceso (Nielsen, 2001; Tarragó, 2000).

Una propuesta que revisa la cronología de este momento ha sido la de Otero y Rivolta (Otero y Rivolta, 2015; Rivolta, Otero y Greco, 2017), quienes analizaron nuevas evidencias de sitios localizados en el sector central de la Quebrada, vinculados a materiales cerámicos definidos como "Isla Polícromo" (sensu Bennet, Bleiler y Sommer, 1948) y tradicionalmente considerados como pertenecientes al período Medio (ca. 600900 d.C.) por diversos autores (Bennet et al., 1948; Pérez, 1973; Tarragó, 1977; Tarragó, González, Avalos y Lamamí, 2010). Sus estudios arrojaron fechados mucho más tardíos para estas manifestaciones culturales, reposicionándolas entre los siglos XII y XIV. A partir de ello, los autores reevaluaron las posibles relaciones entre estas manifestaciones y aquellas consideradas como propias del período Tardío. Así, se planteó que hacia el siglo XII habrían surgido nuevas manifestaciones culturales, relacionadas con grupos que produjeron cerámica del estilo Isla y un desarrollo local, denominado Humahuaca Temprano por los autores mencionados. Ambas manifestaciones habrían sido contemporáneas, aunque habrían mostrado contrastes marcados en la localización de los sitios y en la construcción del paisaje. Dichos contrastes estarían vinculados con el posible origen altiplánico de los grupos vinculados a la cerámica Isla, quienes se habrían desplazado hacia la Quebrada de Humahuaca con posterioridad a la caída de Tiwanaku, compartiendo este espacio con grupos locales. Hacia el siglo XIV los sitios Isla fueron abandonados, presentando una única ocupación. Por su parte, algunos sitios Humahuaca Temprano fueron abandonados mientras que otros dieron origen a los grandes poblados conglomerados, conocidos como pucara.

En relación con la alfarería del período Tardío en Quebrada de Humahuaca, el Humahuaca Negro sobre Rojo (en adelante N/R) se habría constituido como un estilo de distribución regional (Cremonte, 2006). El mismo fue definido por la presencia de piezas decoradas en negro sobre fondo rojo, y en menor medida en negro y blanco sobre rojo, caracterizándose por la presencia de diseños geométricos que aparecen en las superficies internas de piezas de servicio, y en el exterior y borde interno de vasijas de cocción/almacenamiento (Cremonte, 2006; Cremonte y Solís, 1998; Nielsen, 2001; Runcio, 2009). Este estilo aparece asociado a otros como Angosto Chico Inciso (en adelante ACHI), Pucos Interior Negro Pulido, Pucos Poma (Bennet et al., 1948) y Juella Polícromo (Pelissero, 1969). Si bien el Humahuaca N/R es un estilo regional, se ha propuesto la existencia de variaciones que podrían responder a identidades locales en distintos sectores de Quebrada de Humahuaca (Cremonte, 2006; Ortiz y Delgado, 2002; Runcio, 2010; Scaro, 2009).

\section{La Anexión de Quebrada de Humahuaca al Tawantinsuyu}

Durante la primera mitad del siglo XV, Quebrada de Humahuaca pasó a formar parte del Collasuyu, la provincia meridional del Imperio Incaico. Como han señalado diversos autores (D’Altroy, Williams y Lorandi, 2007; Williams, 2000), la organización política incaica era flexible, presentando una variación notable entre las distintas regiones conquistadas ya que la administración estatal estaba construida sobre sistemas políticos 
preexistentes, utilizando una ideología de reciprocidad y redistribución local de recursos para legitimar su nueva economía. De esta manera, el Imperio estableció diversas estrategias de conquista, que incluían tanto la diplomacia como la violencia, y diferentes estrategias de consolidación de poder, vinculadas con un largo proceso de integración de los grupos sujetos.

Las características de la ocupación incaica de una región dependían del grado de centralización política de las sociedades dominadas y de su aceptación o resistencia a la dominación. La existencia de importantes asentamientos en lugares donde estaba presente la población local y en zonas vacías evidenciaría, de acuerdo a Williams y D'Altroy (1998) ,una ocupación selectivamente intensiva en zonas productivas estratégicamente ubicadas. Esto indicaría que el Imperio planificaba su gobierno en relación a las situaciones locales pero teniendo en cuenta un diseño a gran escala, favoreciendo a ciertos grupos y utilizando a las élites locales para ayudar a establecer y mantener el gobierno. Williams (2000) propuso que la presencia de grupos favorecidos quedaría evidenciada por la circulación de ciertos estilos cerámicos en canales paralelos a los del Inca Imperial, como Yavi Chico, Inca Pacajes o Inca Paya.

En Quebrada de Humahuaca, las políticas estatales son visibles a partir de la presencia de remodelaciones en los asentamientos conglomerados establecidos en el período Tardío, como en La Huerta (Palma, 1997; Raffino y Alvis, 1993), Campo Morado (Fernández Do Rio, 2010), Pucara de Perchel (Scaro, 2009), Pucara de Tilcara (Otero, 2013; Tarragó y Albeck, 1997; Zaburlín, 2009) o Pucara de Volcán (Cremonte y Scaro, 2010; Fumagalli, 1998). Los centros administrativos fueron establecidos en la mayoría de los sitios preincaicos de la región (Nielsen, 2001; Raffino y Alvis, 1993). Las remodelaciones de los sitios preexistentes llevadas a cabo por la administración estatal se vincularían con la recreación incaica del paisaje de las comunidades conquistadas, donde la arquitectura habría sido un acto simbólico de apropiación del territorio basado en un doble juego de integración y segregación entre lo local y lo imperial (Cremonte y Williams, 2007).

La remodelación del paisaje llevada a cabo por el Imperio significó el abandono total o parcial de algunos sitios como Los Amarillos (Nielsen y Walker, 1999) o el Pucara de Juella (Leibowicz, 2013; Nielsen, Hernandez Llosa y Rivolta, 2004), reforzando los cambios introducidos por la administración incaica en el paisaje preexistente. El caso de Los Amarillos, considerado como centro político de los Omaguacas (Sica, 2008; Sica y Sánchez, 1996) podría indicar que los Incas reorganizaron las relaciones sociales y de poder preexistentes en Quebrada de Humahuaca, tal como propone Nielsen (2006; Nielsen y Walker, 1999).

Con la llegada de los Incas a la Quebrada, la alfarería adquirió nuevos modos de representación, vinculados con parámetros estatales de uso y producción. Diversos investigadores (Cremonte y Solís, 1998; Deambrosis y De Lorenzi, 1973; Nielsen, 2007; Runcio, 2009, 2012) buscaron caracterizar la cerámica local de este momento haciendo hincapié en la aparición de formas típicamente incaicas pero de manufactura local, dando preeminencia a los cambios morfológicos por sobre las variantes decorativas de las vasijas, tal como señala Otero (2013).

Respecto de la cerámica local característica del PT, se sostuvo que la misma habría mantenido su vigencia sin presentar variaciones en cuanto a forma o decoración (Nielsen, 2001; Runcio, 2009, 2012). Sin embargo, no se han hecho estudios que permitan identificar atributos que diferencien la cerámica local producida y consumida durante el período Incaico de la de momentos previos. Esto, no sólo en relación al estilo Humahuaca N/R, sino también a Pucos Interior Negro Pulido o a piezas ACHI. Avances respecto a este tema fueron realizados por Cremonte y Solís (1998) para el 
sector centro-sur en el análisis de la cerámica de los basureros de Pucara de Volcán y por Otero (2013) para el Pucara de Tilcara.

Si bien es cierto que los momentos tardíos de la historia prehispánica han sido los más estudiados en Quebrada de Humahuaca, la revisión de las investigaciones realizadas en la región permite plantear nuevos interrogantes. Particularmente en relación con la alfarería, se ha planteado la existencia de un estilo regional, denominado Humahuaca N/R, avanzando muy poco sobre las diferencias al interior de Quebrada de Humahuaca. Asimismo, se ha planteado que este estilo local había continuado siendo producido y consumido sin cambios bajo la dominación incaica, sin realizarse un estudio detallado a nivel morfo-decorativo que pueda o no dar cuenta de ello. Estos aspectos son los que se busca abordar en esta oportunidad.

\section{El sector centro-sur en Quebrada de Humahuaca}

La Quebrada de Humahuaca es un estrecho valle que se extiende a lo largo de $120 \mathrm{~km}$ en el centro de la provincia de Jujuy (Argentina) y está delimitado por altas cadenas montañosas que se alinean en dirección norte-sur. Este valle se caracteriza por presentar una gran heterogeneidad natural (Reboratti, 2003), generada por la combinación de su ubicación subtropical, una compleja geología, la masa montañosa que la rodea y su marcada pendiente que permite la contigüidad de diversos entornos ambientales.

El sector centro-sur de Quebrada de Humahuaca (Figura 1) está limitado al norte por la Quebrada de Purmamarca y al sur por el Arroyo del Medio. El mismo se caracteriza por la cercanía de las unidades medioambientales y geomorfológicas de Puna (planicie por encima de los $3.000 \mathrm{~m}$ s.n.m. de clima seco y frío), Prepuna (el ámbito de Quebrada de Humahuaca) y Yungas (selva de montaña en las laderas orientales de las sierras subandinas) debido a la disminución de la altura de las cadenas montañosas que enmarcan la Quebrada hacia el Este y el Oeste. Esta situación permite el acceso a una gran variedad de recursos en corta distancia. Quebradas transversales al río Grande, tales como la de Tumbaya Grande al Oeste y la de Huajra al Este, funcionan aún hoy como rápidas vías de acceso hacia la Puna y las Yungas respectivamente.

Estudios recientes realizados en la zona (Scaro, 2015a) han revelado una intensa ocupación prehispánica desde hace por lo menos dos mil años. Los sitios de momentos tardíos de mayor importancia incluyen El Pobladito, Pucara de Volcán y Esquina de Huajra. El Pobladito es un asentamiento de dos hectáreas que se localiza en el interior de la Quebrada de Tumbaya Grande, su excavación reveló una única ocupación datada entre inicios del siglo XIII y finales del XIV (Scaro, 2015b). Pucara de Volcán y Esquina de Huajra se localizan en la margen occidental del río Grande. El primero de ellos corresponde a un extenso asentamiento de más de siete hectáreas con una ocupación continuada entre los siglos XIII y XVI, mostrando una importante remodelación incaica (Cremonte y Scaro, 2010; Fumagalli, 1998). Esquina de Huajra es un asentamiento incaico, localizado en un espacio no ocupado previamente por las poblaciones locales. Las excavaciones realizadas hasta la fecha dan cuenta de la existencia de un área doméstica pero también de un espacio de entierros, que probablemente habría funcionado como un lugar para rituales vinculados con el culto a los difuntos (Scaro y Cremonte, 2012).

\section{Propuesta para el estudio de la alfarería}

La alfarería, en tanto una de las labores más generalizadas del pasado, permite aproximarse a una amplia gama de actividades (Skibo y Feinman, 1999), a la vez que 

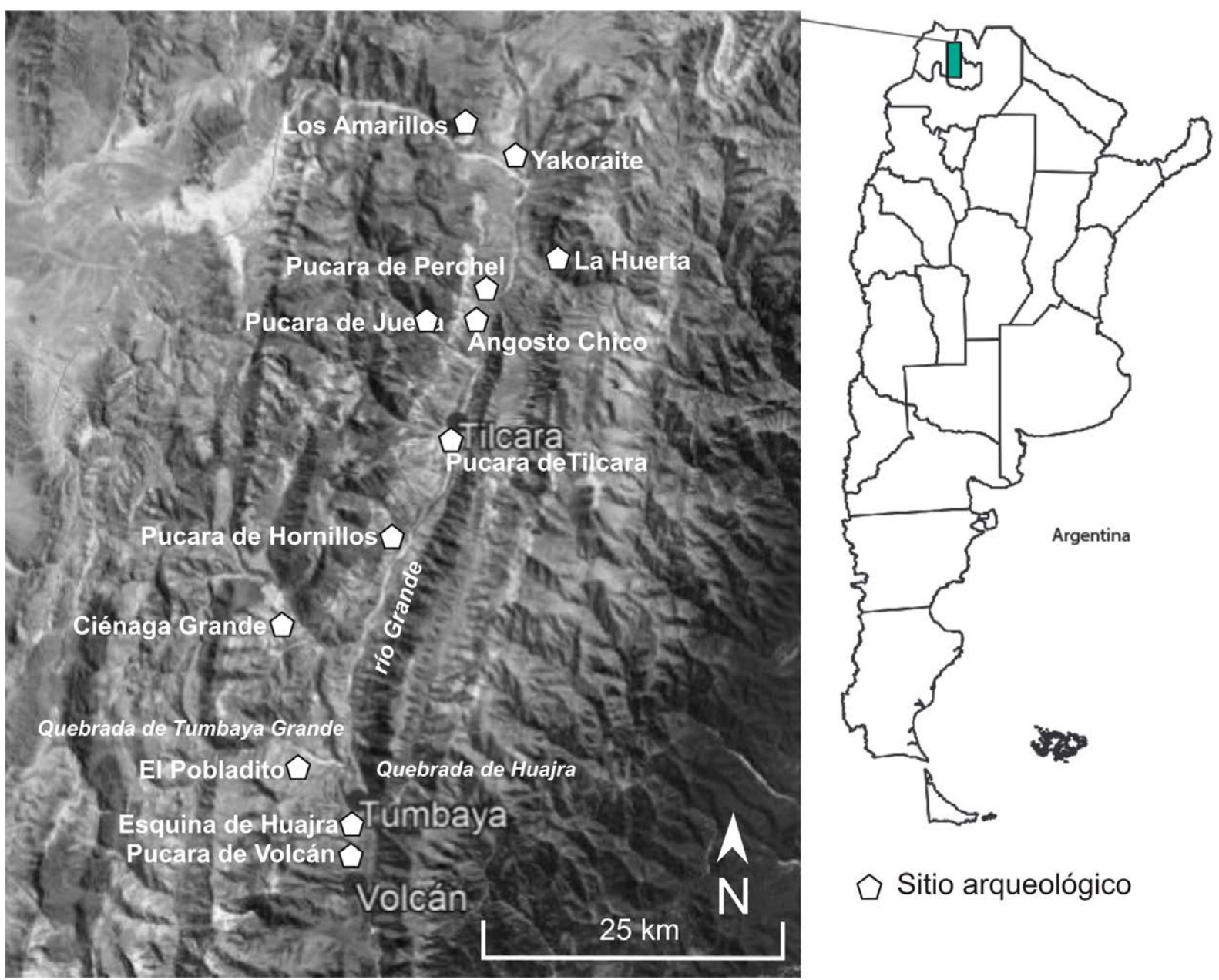

\section{Sitio arqueológico}

Figura 1. Mapa del sector centro-sur de Quebrada de Humahuaca con la localización de los sitios arqueológicos mencionados en el texto.

brinda información acerca de vinculaciones con otras regiones. El establecimiento de un repertorio morfo-iconográfico del sector centro-sur, su comparación con la alfarería de distintos sitios de Quebrada de Humahuaca y la consideración de los cambios introducidos por la conquista incaica, resultaron una vía de acceso a cuestiones identitarias, sociales y políticas de los grupos que fabricaron y manipularon estos objetos.

Al comprender la materialidad como la dimensión material de la práctica, inserta dentro de un proceso por el cual los objetos y los agentes humanos se constituyen recíprocamente (Miller, 2005), vemos que las actividades diarias y los objetos cotidianos son socialmente significativos (Knappett, 2008). Así, es necesario enfocarse en un aspecto más amplio de la vida social que va más allá de "lo simbólico", considerando que no solamente aquellos bienes vistos como especiales, estéticos o mágicos poseen significado.

Los objetos permiten que la experiencia en una región se establezca como un espacio social compartido, en tanto circulan a través de largas distancias y participan en diversas transacciones y contextos de uso. Los objetos que viajan vinculan a las personas con los lugares, construyendo al paisaje como una creación dinámica y colectiva (Lazzari, 2005). En este sentido, el estudio de objetos de origen no local permite establecer la amplitud del paisaje de las sociedades del pasado. La cerámica constituye un indicador 
clave en tanto permite establecer vínculos con otras regiones a nivel iconográfico, morfológico y en sus aspectos de manufactura.

A su vez, la materialidad juega un rol esencial en la construcción, expresión y negociación de la identidad de un grupo, ya que se establece como el contexto en el cual los individuos interactúan, se relacionan y negocian su posición social (Mac Sweeney, 2011). De esta manera, la presencia y participación activa de la materialidad en las prácticas sociales permite poner en relevancia los distintos lugares de los cuales provienen los objetos usados en la vida cotidiana de los actores, así como transmitir la memoria del grupo.

El estudio de la cerámica fue abordado desde la perspectiva de análisis estilísticos, considerando que el estilo no está separado de los contextos sociales que dan a la cultura material su valor social, tal como señalan Conkey y Hastorf (1990). Desde esta perspectiva activa, el estilo es entendido como un modo de representación socialmente construido y que posee una configuración particular cuyos contenidos sólo pueden ser interpretados en relación con el contexto en el cual es producido y consumido (Bugliani, 2010). Partiendo de esta propuesta, consideramos que los aspectos iconográficos, morfológicos y tecnológicos están interrelacionados, configurando un modo de hacer particular, vinculado con los esquemas prácticos utilizados cotidianamente por las personas que pensaron, utilizaron y descartaron las vasijas. Un estilo puede comprenderse así como un conjunto de hábitos, prácticas y capacidades encarnadas (Scattolin, 2007).

Por otra parte, el análisis estilístico de las vasijas cerámicas permite registrar ciertas regularidades respecto de su decoración, tratamiento de superficie y forma. Dichas regularidades podrían transmitir temas de conocimiento colectivo relacionados con política, memoria e identidad, formando parte del complejo sistema de comunicación andino planteado por diversos autores (Martínez, 2010; Troncoso, 2005) para representaciones gráficas plasmadas en distintos soportes. En este sentido y como propusiera Hodder (1990), el estilo es poder en tanto crea relaciones sociales e ideologías a partir de la fijación de significados.

En esta oportunidad nos centramos en las variables morfológicas y decorativas, en tanto el análisis interrelacionado de estas dimensiones posibilita el conocimiento de las conductas que les dieron origen, de las prácticas sociales relacionadas con su distribución y consumo, de los cambios cronológicos y de los posibles contactos entre distintos grupos (Cremonte, 2005). Esto no significa desconocer la importancia de la dimensión tecnológica en el análisis estilístico, sin embargo el abordaje de la misma excede los objetivos de este trabajo.

A partir del análisis estilístico se buscó elaborar una clasificación que incluyera el repertorio de formas y decoraciones presentes en el sector en relación con la creación, re-creación y transmisión de una identidad común puesta en juego en la materialidad durante el PT y también en momentos incaicos. Para ello se tomaron como base los lineamientos propuestos por Bugliani (2010) para el análisis morfológico e iconográfico de las vasijas, considerando las categorías formales establecidas para Quebrada de Humahuaca (Nielsen, 2001, 2007; Ortiz y Delgado, 1997; Otero, 2006).

El análisis morfológico de las vasijas fue establecido tomando como base la propuesta de Balfet, Fauvet Berthelot y Monzón (1983). En principio, se establecieron Grupos Morfológicos Generales (pucos, escudillas, fuentes, platos, baldes, vasos chatos, ollas, cántaros, tinajas y aríbalos) a partir de la relación entre la altura de las piezas y su diámetro máximo, mínimo y de abertura. Cada grupo fue subdividido en variedades de acuerdo a sus puntos del perfil, las características del borde y del cuello de las 
1. Para una descripción y discusión detallada de la alfarería no local de distintos períodos recuperada en el sector centro-sur de Quebrada de Humahuaca ver Scaro (2015a). vasijas. Este enfoque resultó útil a la hora de realizar una clasificación morfológica de un conjunto altamente fragmentado como el que se enfrenta en este caso.

Posteriormente, los Grupos Morfológicos fueron divididos de acuerdo a su funcionalidad, considerando que la forma de una vasija suele estar vinculada con las funciones para las cuales fue creada (Cremonte y Bugliani, 2009). De esta manera y siguiendo a Rice (1987), pucos, platos, escudillas, fuentes, baldes y vasos chatos fueron considerados como vasijas de servicio, entendidas como piezas irrestrictas de fácil acceso cuyos tamaños corresponden a porciones individuales o grupales. Ollas, cántaros, tinajas y aríbalos fueron consideradas como vasijas para almacenamiento, preparación y/o cocción de alimentos, en tanto formas restringidas o muy restringidas con sus orificios modificados para poder cerrarlos o utilizarlos para verter.

El análisis de las representaciones visuales inscritas en la cerámica incluyó la identificación de las técnicas decorativas utilizadas, el establecimiento del protocolo de elementos decorativos y reglas de combinación de los mismos. El enfoque utilizado para el análisis del diseño de las piezas cerámicas sigue los lineamientos propuestos por Jernigan (1986), quien plantea un acercamiento no jerárquico a los elementos decorativos, buscando identificar unidades pero sin dar por sentado que existen niveles entre las mismas relacionados con etapas en su planificación o ejecución. Posteriormente, se procedió a analizar los diversos arreglos que los mismos presentan en las vasijas, estableciendo reglas de combinación que ordenan secuencialmente las representaciones, siguiendo los lineamientos propuestos por Shanks y Tilley (1987) y Bugliani (2010), y considerando los efectos logrados por estas combinaciones y sus sucesiones sobre las vasijas.

\section{El análisis de la alfarería local}

Se analizó un total de 285 vasijas (Figura 2, Tabla 1) fragmentadas ( $\mathrm{n}=257: 285)$, parcialmente enteras $(n=13: 285)$ o enteras $(n=15: 285)$ correspondientes a distintos tipos y estilos identificados para la región. Se trabajó a partir del Número Mínimo de Vasijas, agrupando los fragmentos a partir de sus tratamientos y acabados de superficie. Esta muestra fue recuperada en contextos pre-Incaicos $(n=74: 285)$ e Incaicos $(n=211: 285)$. La cerámica del PT analizada para este artículo incluyó aquella de El Pobladito (Scaro, 2015a) y de los niveles inferiores de los Basureros Tum1B1 y Tum1B3 de Pucara de Volcán (Cremonte y Solís, 1998). Fue posible identificar estilos y tipos locales propios del período en cuestión: Humahuaca N/R, ACHI, Pucos Interior Negro Pulido, vasijas alisadas con engobe rojo, y ordinarias. La cerámica de manufactura no local $^{1}$ corresponde a Pucos Bruñidos.

El material de contextos incaicos incluyó los materiales recuperados en Esquina de Huajra y Pucara de Volcán, ya que de acuerdo a las evidencias halladas hasta la fecha (Scaro, 2015a, 2015b) El Pobladito habría estado deshabitado durante este momento. El análisis del material de estos asentamientos permitió establecer la continuidad de los estilos hallados en El Pobladito, situación ya observada por Cremonte y Solís (1998) en los basureros de Pucara de Volcán. Se registraron piezas Humahuaca N/R, ACHI, Pucos Interior Negro Pulido y Humahuaca-Inca, así como vasijas ordinarias, alisadas y pulidas sin decoración pintada. Están presentes también estilos no locales, como Inca Pacajes, Inca Paya, Yavi-Chicha, Pucos Bruñidos y Corrugados.

El análisis morfológico de las vasijas permitió establecer un repertorio compuesto por diez Grupos Morfológicos Generales: pucos, escudillas, fuentes, baldes, platos y vasos chatos dentro de la vajilla de servicio; ollas, cántaros, tinajas y aríbalos dentro de la vajilla de cocción/almacenamiento. De los diez grupos morfológicos mencionados, siete fueron identificados para el PT (Figura 3A), mientras que el total está representado en la alfarería de momentos incaicos (Figura 3B). 


\begin{tabular}{|c|c|c|c|c|c|c|c|c|c|c|c|c|c|c|}
\hline 든 & $\bar{\alpha}$ & 6 & ' & ' & ' & ' & $r$ & $\underset{-1}{0}$ & & $\forall$ & ' & ' & ' & ' \\
\hline$\underline{Z} \frac{E}{<}$ & 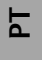 & $\lambda$ & $\infty$ & ' & ' & ' & ' & $\lambda$ & ' & ' & ' & ' & 1 & 1 \\
\hline $\begin{array}{l}\text { 을 } \\
\text { 을 } \\
\frac{1}{2}\end{array}$ & $\bar{a}$ & ' & ' & ' & ' & ' & $m$ & 1 & ' & 6 & ' & ' & ' & ' \\
\hline \multirow{2}{*}{$\stackrel{\frac{\pi}{\pi}}{\stackrel{.}{=}}$} & $\bar{\alpha}$ & $r$ & $r$ & ' & ' & ' & $r$ & ' & ' & ' & ' & ' & ' & ' \\
\hline & $\stackrel{5}{a}$ & $r$ & ' & ' & ' & ' & ' & ' & ' & ' & ' & ' & ' & ' \\
\hline \multirow{2}{*}{ 递 } & $\bar{a}$ & $\forall$ & ন & ' & ' & & ' & $N$ & ' & ㄱ & ' & ' & $\forall$ & ' \\
\hline & $\stackrel{5}{a}$ & $N$ & ' & ' & ' & ' & ' & $r$ & ' & ' & ' & ' & 1 & ' \\
\hline \multirow{2}{*}{$\frac{\tilde{x}}{\overline{0}}$} & $\bar{\alpha}$ & ' & ㄱ & ' & ' & $r$ & ' & $m$ & ' & ' & ' & $r$ & ' & ' \\
\hline & \llcorner & ' & $\forall$ & ' & ' & ' & ' & $r$ & ' & ' & ' & ' & ' & ' \\
\hline \multirow{2}{*}{$\begin{array}{l}\frac{0}{U} \\
\frac{1}{2} \\
\sim \\
\text { Z }\end{array}$} & $\bar{\alpha}$ & $\lambda$ & ' & ' & ' & ' & ' & ' & ' & $\stackrel{m}{\rightarrow}$ & ' & ' & ' & ' \\
\hline & \llcorner & $a$ & ' & ' & $r$ & ' & $r$ & ' & ' & ' & ' & ' & ' & ' \\
\hline$\frac{\mathscr{d}}{\frac{0}{\pi}}$ & $\bar{\alpha}$ & ' & $r$ & ' & ' & ' & ' & ' & ' & $r$ & ' & ' & ' & ' \\
\hline$\frac{\stackrel{n}{\frac{\pi}{\pi}}}{\alpha}$ & $\bar{\alpha}$ & ' & ' & ' & ' & ' & 6 & ' & ' & $\Lambda$ & $ナ$ & $r$ & ' & - \\
\hline \multirow{2}{*}{ 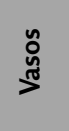 } & $\bar{\alpha}$ & ' & $\checkmark$ & ' & ' & ' & ' & ' & ' & ' & ' & 1 & ' & ' \\
\hline & 站 & $N$ & $m$ & ' & $r$ & ' & ' & ' & ' & & ' & 1 & ' & ' \\
\hline \multirow{2}{*}{ 导 } & $\bar{\alpha}$ & $r$ & ' & ' & $r$ & & $N$ & ' & ' & $\infty$ & ' & ' & ' & ' \\
\hline & 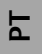 & $N$ & ' & ' & ' & ' & ' & ' & ' & ' & 1 & ' & ' & ' \\
\hline \multirow{2}{*}{ 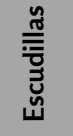 } & $\bar{\alpha}$ & $N$ & ' & & $r$ & ' & $\forall$ & ' & ' & ન & $r$ & ' & 1 & ' \\
\hline & $\mathfrak{n}$ & $\forall$ & ' & ' & $r$ & 0 & 0 & ' & ' & ' & ' & ' & ' & ' \\
\hline \multirow{2}{*}{ 气̆ } & $\bar{\alpha}$ & ' & $N$ & ન & $m$ & ' & $N$ & ' & $m$ & 아 & ' & ' & ' & ' \\
\hline & 占 & $a$ & $N$ & $r$ & 6 & $r$ & ' & ' & ' & ' & ' & ' & ' & ' \\
\hline & & $\stackrel{\Re}{\mathbf{z}}$ & 웅 & 롬 & $\begin{array}{l}\dot{3} \\
\dot{a} \\
\dot{z}\end{array}$ & نَ بَ & $\dot{\bar{\alpha}}$ & 売 & 오 & $\begin{array}{l}\frac{J}{Z} \\
\vdots \\
\vdots \\
\Xi\end{array}$ & $\gtreqless$ & 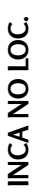 & s & $\frac{j}{\frac{j}{\alpha}}$ \\
\hline
\end{tabular}

Tabla 1. Cantidad de vasijas para los Estilos/Tipos y Grupos Morfológicos Generales definidos para el sector centro-sur de la Quebrada.

Referencias. PT: período Tardío; PI: período Incaico; N/R: Humahuaca Negro sobre Rojo; N.PUL.: Interior Negro Pulido; BRU: Pucos Bruñidos; AL.ENG.: Alisado con Engobe; ORD: Ordinario; HUM INCA: Humahuaca-Inca; PUL.: Pulidos Lisos; I-P: Inca Paya; POR.POL: Portillo Policromo; INCA PAC: Inca Pacajes; INCA NO LOC: Incaico no local; ACHI: Angosto Chico Inciso; CAS: Casabindo. 


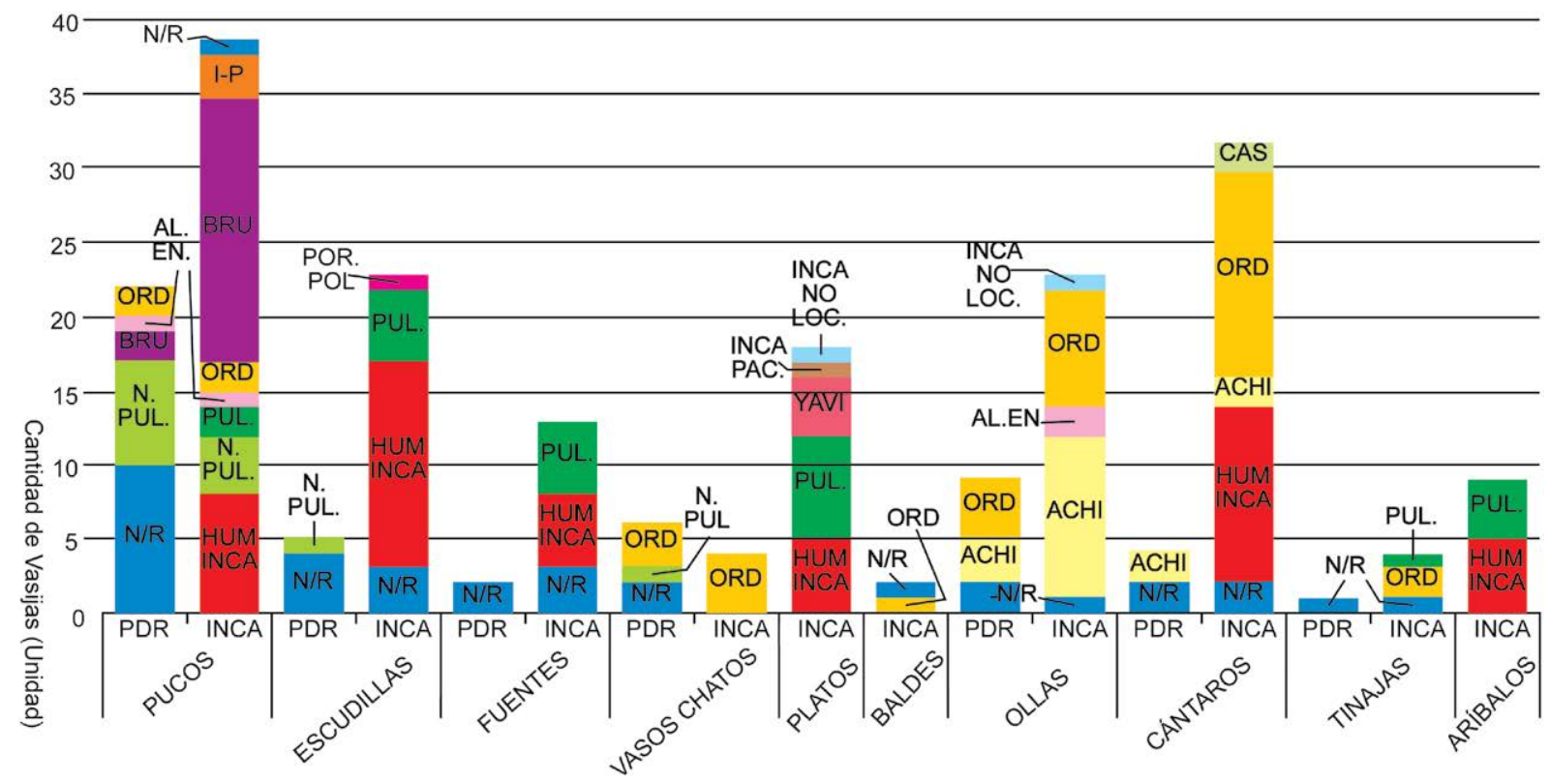

Figura 2. Cantidad de vasijas para los Estilos/Tipos y Grupos Morfológicos Generales definidos para el sector centro-sur de la Quebrada. Referencias. PT: período Tardío; INCA: período Incaico; N/R: Humahuaca Negro sobre Rojo; N.PUL.: Interior Negro Pulido; BRU: Pucos Bruñidos; AL.ENG.: Alisado con Engobe; ORD: Ordinario; HUM INCA: Humahuaca-Inca; PUL.: Pulidos Lisos; I-P: Inca Paya; POR.POL: Portillo Policromo; INCA PAC: Inca Pacajes; INCA NO LOC: Incaico no local; ACHI: Angosto Chico Inciso; CAS: Casabindo.

Al comparar el repertorio morfológico de momentos prehispánicos tardíos, se puede observar que bajo la anexión de la zona al incario las vasijas presentan una variación morfológica mayor, identificándose nuevas variedades entre las que se destacan las fuentes que en general son menos profundas que las observadas en El Pobladito, pareciéndose a platos grandes. Asimismo, están presentes formas novedosas como platos, aríbalos y ollas con pie que son típicas de la vajilla incaica. Los platos son predominantes tanto en el centro del imperio como en las provincias, mientras que las otras vasijas son las piezas más abundantes en sitios de las provincias (Bray, 2004). Para el sector central de Quebrada de Humahuaca, los baldes han sido considerados como parte de la vajilla del PT que perdurarían durante el Incaico (Nielsen, 2001, 2007). En Tumbaya, su presencia fue registrada en Esquina de Huajra (de momentos incaicos) y en la colección Gatto (1946) de Pucara de Volcán, aunque los contextos de hallazgo de esta última carecen de controles cronométricos. El hecho de que los baldes estén ausentes en los niveles inferiores de los basureros Tum1B1 y Tum1B3 permite pensar que serían también de época incaica en Pucara de Volcán.

El análisis morfológico de la cerámica se combinó con el decorativo, buscando identificar elementos decorativos y reglas de combinación entre ellos. El mismo fue realizado sobre 180 vasijas con decoración pintada, modelada o con desplazamiento de pasta. Los elementos decorativos fueron reconocidos por su repetición en distintos recipientes, identificándose 13 para el conjunto cerámico del PT (Figura 4A). Entre ellos, nueve son pintados y corresponden al Humahuaca N/R, mientras que los cuatro restantes, ejecutados mediante desplazamiento de pasta, pertenecen a piezas ACHI. Para el conjunto de momentos Incaicos se identificaron 32 elementos (Figura 4B) que incluyen algunos de los registrados para el momento previo, aunque con variaciones.

Los elementos decorativos se organizan de maneras diversas en las vasijas, variando la composición del diseño según su disposición en el campo decorativo y la relación entre elementos. Para comprender este orden secuencial de las representaciones, se identificaron 14 reglas de combinación (Figura 5): las seis primeras corresponden al PT y continuaron en uso durante el Incaico, mientras que las ocho restantes constituyen innovaciones del momento incaico. 


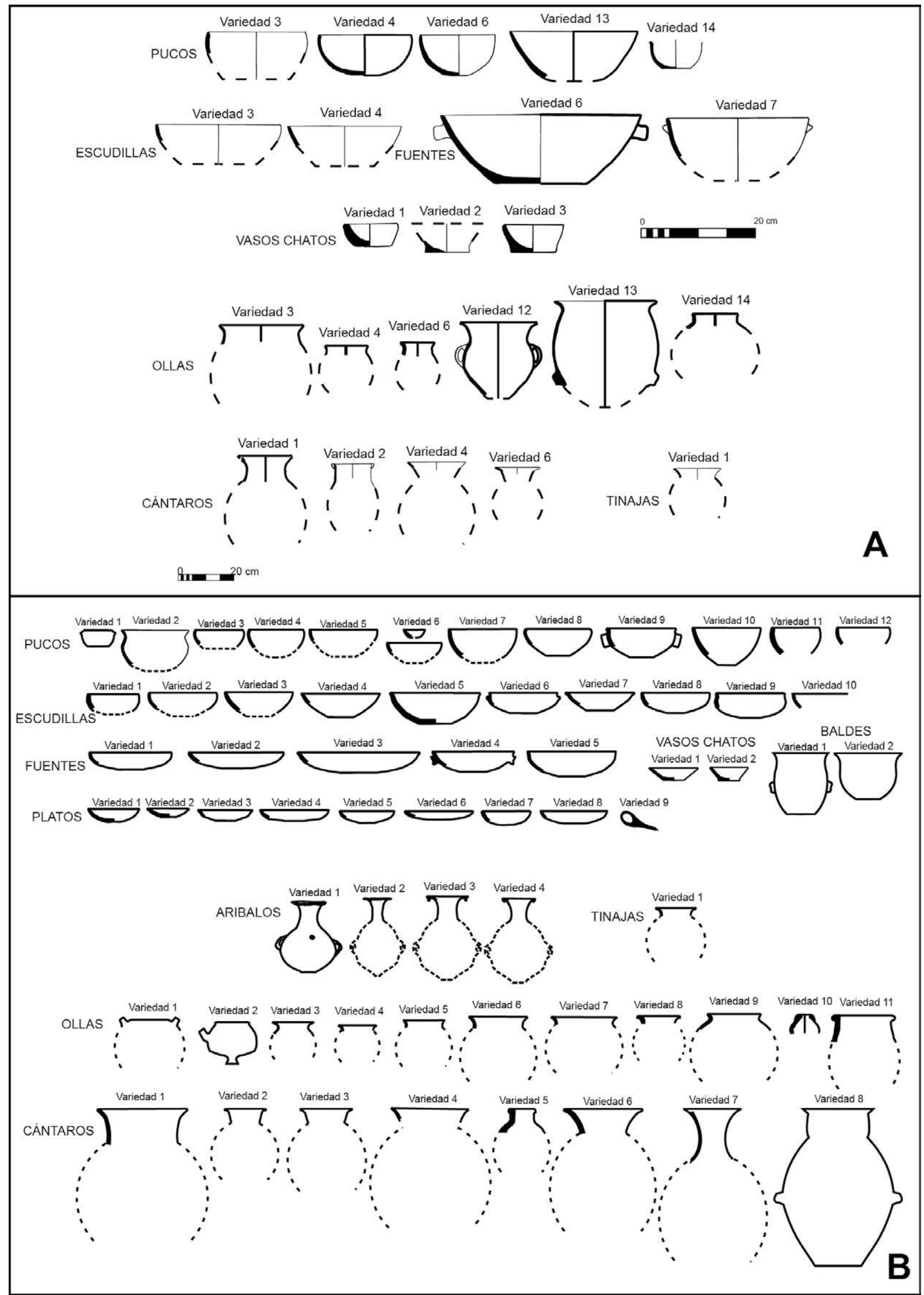

Figura 3. Repertorio morfológico de vasijas del sector centro-sur de la Quebrada. A) vasijas de servicio (arriba) y de cocción y almacenamiento (abajo) preincaicas; B) vasijas de servicio (arriba) y de cocción/almacenamiento (abajo) del período Incaico. 


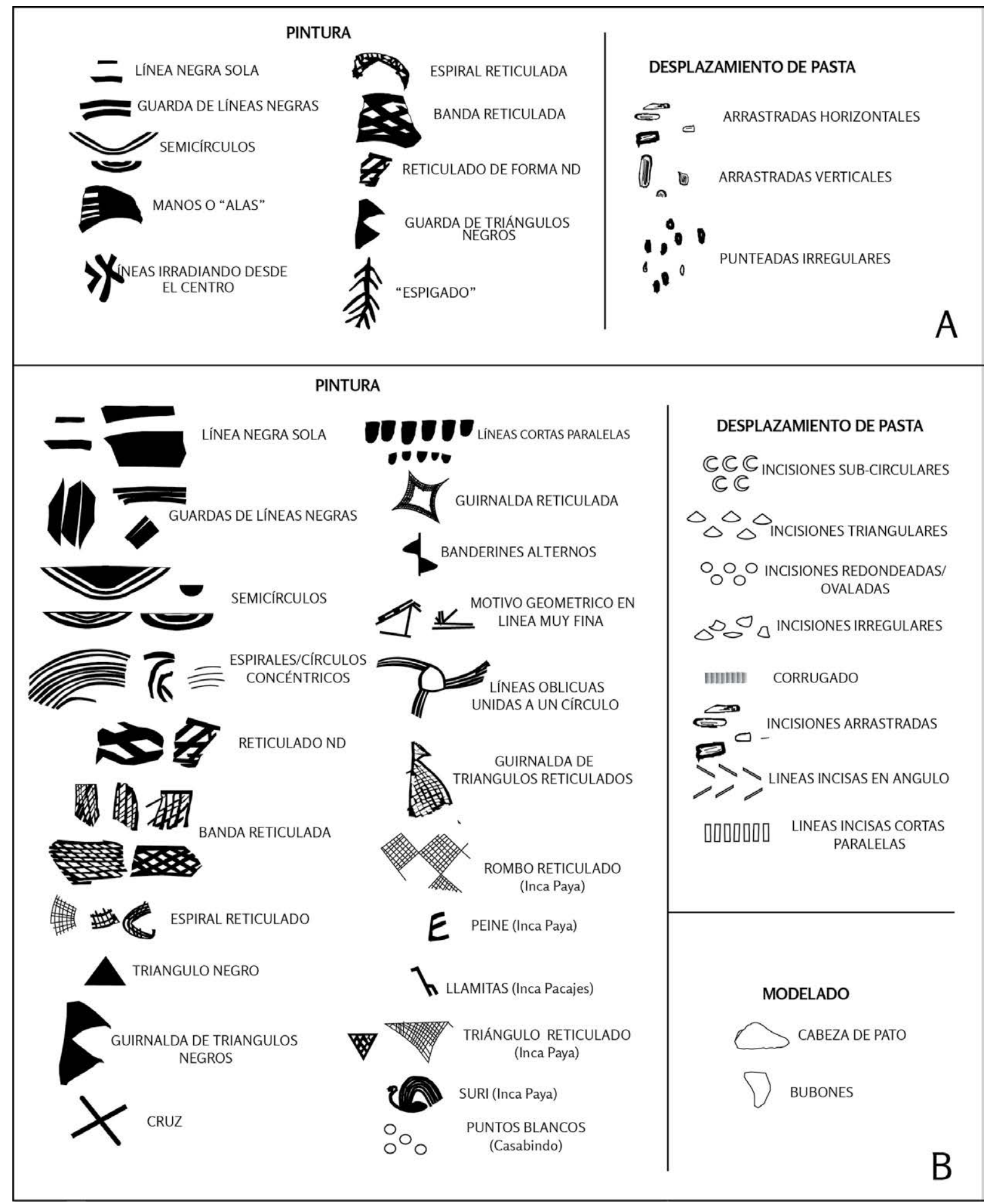

Figura 4. Elementos y técnicas decorativas identificados en el conjunto cerámico del sector centro-sur de la Quebrada. A) período Tardío; B) momentos incaicos.

Las Reglas 11 y 12 resultaron más complejas y corresponden a las configuraciones halladas en el interior de escudillas recuperadas enteras o parcialmente enteras, indicando que las configuraciones de los esquemas decorativos probablemente hayan sido más complejas de lo que se puede apreciar en los fragmentos. Por su parte, la 


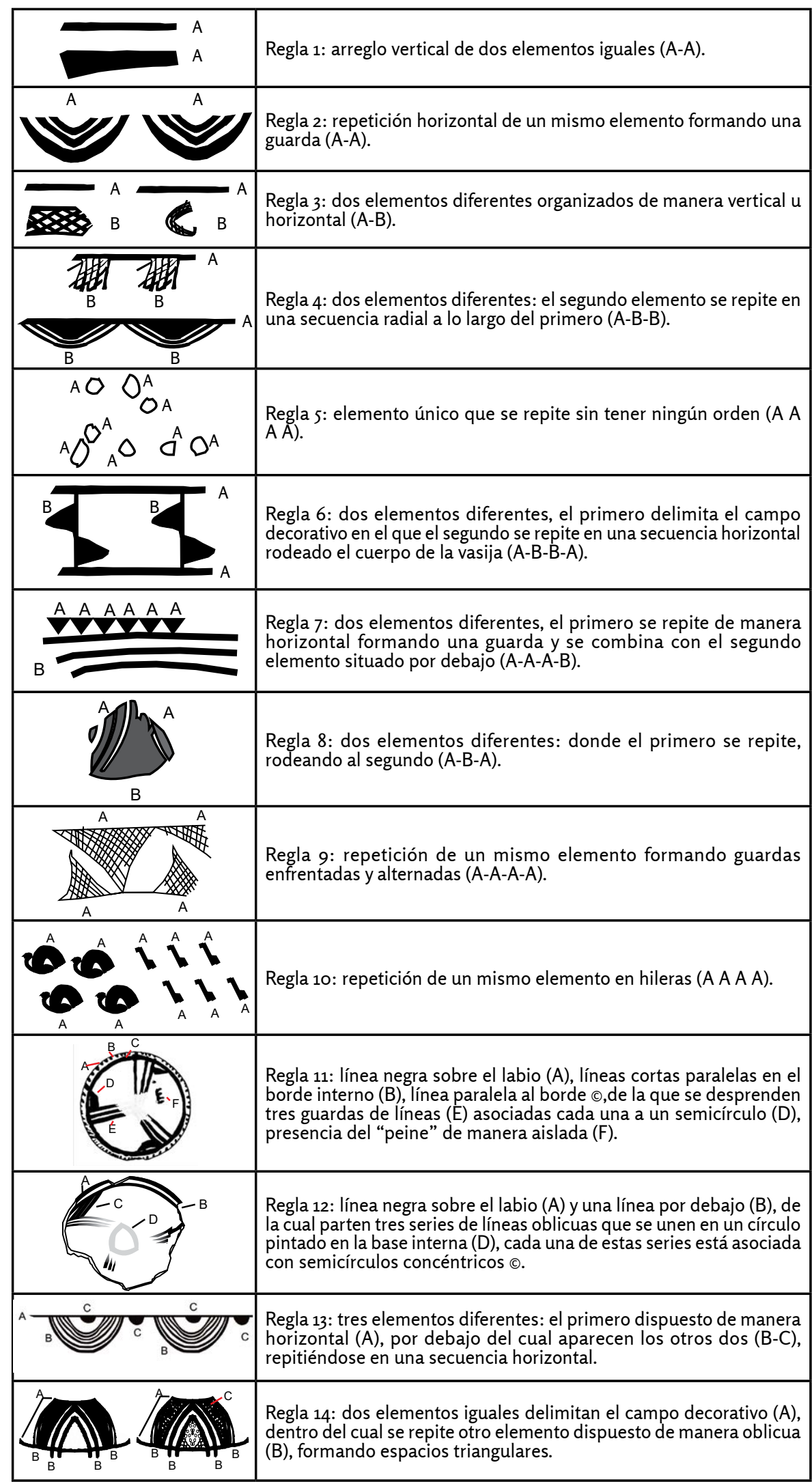

Figura 5. Reglas de combinación identificadas en la cerámica de los períodos Tardío e Incaico del sector centro-sur de la Quebrada. 
regla 14 corresponde a la decoración de cántaros Casabindo Pintado (Zaburlín, 2012) y presenta una variación ya que esta misma configuración puede presentar puntos blancos $(\mathrm{C})$ en los espacios triangulares.

Las reglas de combinación propuestas formarían parte del complejo universo de sistemas andinos de registro, identificado por diversos autores en distintos soportes (Martínez, 2010; Troncoso, 2005, entre otros) y que incluiría también mitos, narraciones, bailes, teatralizaciones, música, tejidos, khipus, tablas, varas, keros y paneles de arte rupestre. Estos sistemas andinos de comunicación trasmitirían ciertos temas de conocimiento colectivo, probablemente relacionados a la política, la memoria y la identidad. Los signos presentes en ellos estarían organizados de acuerdo a lógicas constructivas propias que podrían ser recuperadas, si bien parcialmente, gracias a la presencia de ciertas regularidades.

Es probable que las reglas y estructuras de combinación identificadas en la alfarería del sector centro-sur de la Quebrada estén relacionadas con pautas orales andinas, al igual que las formas visuales narrativas de los vasos kero, vinculadas con pautas de la tradición oral quechua (Martínez y Martínez, 2013). Esta relación aún no ha sido indagada para el caso de la alfarería del NOA, aunque resultaría prometedor para avanzar en la comprensión de los mensajes inscritos en la cerámica.

\section{Continuidades, cambios y transformaciones en la cerámica local}

El análisis cerámico realizado permitió comparar los conjuntos alfareros locales de los momentos prehispánicos tardíos, buscando identificar las transformaciones introducidas bajo la dominación incaica de la zona.

\section{Humahuaca Negro sobre Rojo y Humahuaca-Inca}

Como ya fuera mencionado, el estilo Humahuaca N/R se destaca por su gran dispersión en Quebrada de Humahuaca y su alta incidencia en el registro arqueológico. La muestra del sector centro-sur analizada incluye 57 vasijas de este estilo, de las cuales 36 corresponden al PT y 21 al período Incaico. Fue posible detectar algunos cambios a nivel morfológico y decorativo que permiten diferenciar la cerámica de momentos preincaicos de aquella más tardía. Una diferencia se vincula con el significativo incremento de vasijas pulidas, especialmente en el caso de la vajilla de servicio, en clara contraposición a lo observado para el PT. A nivel morfológico, existe una continuidad en la vajilla de servicio Humahuaca N/R (Figura 6), en las variedades de perfil simple y borde directo de pucos (variedad 6) y escudillas (variedad 3), aunque asociadas a nuevas decoraciones, y en las tinajas (variedad 1), ollas (variedad 4) y los cántaros (variedades 1, 3 y 6), decorados con semicírculos concéntricos en su borde interno.

Como puede verse en la Figura 6, no se observó continuidad a nivel morfológico en las fuentes, aunque las Humahuaca N/R de variedades 1 y 5 de momentos incaicos son profundas como las registradas para momentos preincaicos. El conjunto de vasijas de servicio del período Incaico se completa con un balde (variedad 2) decorado con una línea negra en el labio, cuya superficie externa es alisada y la interna pulida. Esta característica podría vincularse con su función como contenedor de líquidos, ya que como señaló Rice (1987), el pulido de la superficie de una vasija contribuiría a su impermeabilización.

En relación con los elementos decorativos de la vajilla Humahuaca N/R, se ha observado la continuidad de líneas negras, semicírculos y la banda y espiral reticulada. La banda reticulada y la línea negra en el labio aparecen tanto en las vasijas de servicio como en 


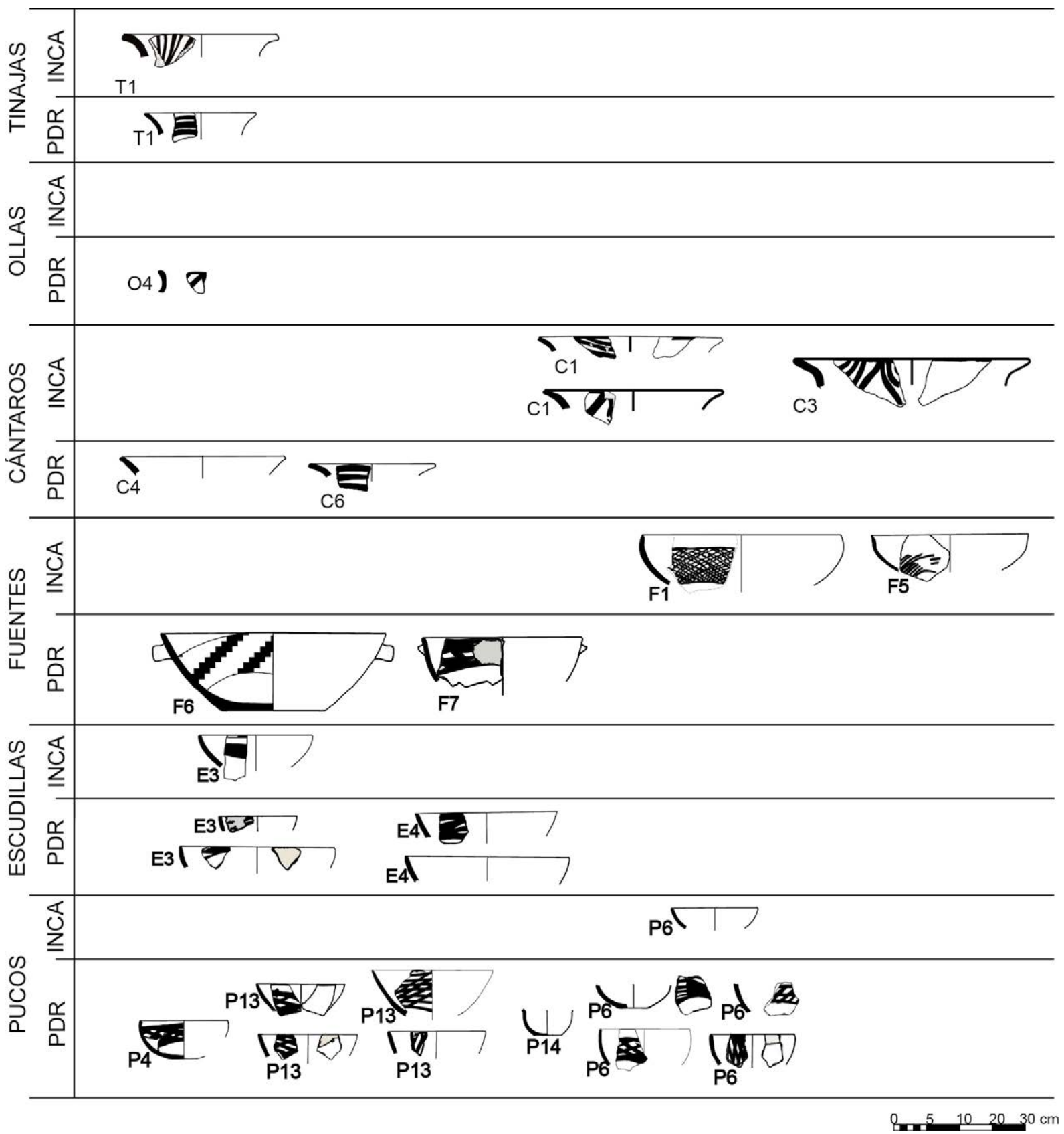

Figura 6. Continuidades e innovaciones morfológicas en las vasijas Humahuaca N/R de los períodos Tardío e Incaico (la sigla junto a cada vasija indica su variedad morfológica). Se grafican las piezas más representativas.

las de cocción/almacenamiento. Para el PT, las manos o "alas" son elementos decorativos exclusivos de la vajilla de servicio, mientras que los semicírculos concéntricos aparecen sólo en el borde interno de vasijas de cocción/almacenamiento. Las espirales o círculos concéntricos han sido señaladas como elementos propios del Humahuaca N/R durante el PT (Nielsen, 2001, 2007; Runcio, 2009, 2010), aunque en el sector centro-sur de la Quebrada aparecen sólo para momentos incaicos. A partir de esto, se propone que los elementos mencionados reflejan innovaciones del estilo Humahuaca N/R introducidas durante el Incaico en el sector centro-sur.

Los elementos decorativos del PT del sector centro-sur se caracterizan por estar ejecutados en líneas medias a gruesas $(>4 \mathrm{~mm})$ y por reticulados de malla abierta en 
ángulo inferior a $90^{\circ}$, a los que se denominó "reticulados romboidales". En momentos Incaicos, si bien continuaron utilizándose los "reticulados romboidales", resultan recurrentes los diseños reticulados de trazo fino $(2 \mathrm{a} 4 \mathrm{~mm})$ y de malla cerrada con líneas que se entrecruzan formando ángulos de $90^{\circ}$. Este tipo fue denominado "reticulado cuadrado".

Se ha registrado un fragmento de una vasija de cocción/almacenamiento en El Pobladito con guarda vertical de triángulos negros asociada al "espigado". Este elemento fue observado en una pequeña olla de la colección de Pucara de Volcán (Ortiz y Delgado, 1997) decorada con el "espigado" asociado a dos bandas reticuladas verticales y a semicírculos concéntricos en el borde interno de la pieza. El "espigado" no fue registrado en sitios de otros sectores de la Quebrada ni tampoco en contextos incaicos. Lo consideramos un elemento propio del sector centro-sur que habría formado parte de los recursos estilísticos en circulación durante el PT.

El Humahuaca-Inca $(n=78: 285)$ retoma algunas variedades morfológicas del PT para pucos, escudillas y cántaros, aunque asociadas a nuevos elementos decorativos. Respecto de las piezas de paredes rectas divergentes y borde directo (puco variedad 13, escudilla variedad 4, fuente variedad 6 de la Figura 6), Cremonte y Solís (1998) y Ortiz y Delgado (2002) señalaron que esta forma de escudillas es predominante en el material de Pucara de Volcán. La alfarería recuperada en El Pobladito muestra que esta forma se repite en pucos y fuentes además de las escudillas, decorados en todos los casos con una banda horizontal de "reticulado romboidal". Se considera, siguiendo a las autoras, que la presencia reiterada de estas vasijas reflejaría un modo de hacer de las poblaciones del sector centro-sur de la Quebrada durante el PT, es decir que podrían ser consideradas referentes identitarios. Durante el período Incaico, se mantienen las escudillas de paredes rectas divergentes (variedad 4) como parte del estilo HumahuacaInca pero desaparecen los pucos y las fuentes de esta variedad. Esto podría dar cuenta de cambios en las formas de expresar la identidad local bajo la administración incaica, manifestada sólo en las escudillas.

Se registraron variedades exclusivas del Humahuaca-Inca (Figura 7) así como la introducción de nuevos grupos morfológicos, como son platos y aríbalos, aunque en baja proporción. A nivel decorativo, el Humahuaca-Inca retoma los elementos ya señalados para el Humahuaca N/R a la vez que se observan otros nuevos, como guirnaldas y triángulos de "reticulado cuadrado", líneas oblicuas que se unen a un círculo, el "peine" y las líneas cortas paralelas en el borde interno. Algunos elementos como semicírculos concéntricos y guarda de líneas negras fueron registrados exclusivamente en vasijas de cocción/almacenamiento preincaicas, mientras que en el período Incaico dichos elementos aparecen también en vasijas de servicio.

En relación con los aríbalos y platos decorados con elementos locales, resulta sugerente la propuesta de Hyslop (1993) en cuanto a que en las provincias del imperio se copiaron las formas más que la decoración, tratándose de construcciones sociales particulares donde se involucraban conceptos significativos para ambas partes y que implicaban una representación del mundo en cuya construcción participaban conquistadores y conquistados.

\section{Angosto Chico Inciso}

El Angosto Chico Inciso fue definido por Bennet et al. (1948) como uno de los estilos propios de Quebrada de Humahuaca para el PT. Madrazo (1970) consideró que sería más apropiado referirse a un "complejo" en tanto incluye una gran variedad de formas y decoraciones que deberían definirse. Posteriormente, Ottonello (1994) caracterizó a las piezas de este estilo como ollas y botellones de cuerpo subglobular, con base circular plana, convexa o acuminada, cuellos cortos y asas en arco labio-adheridas. 


\section{ARÍBALOS}
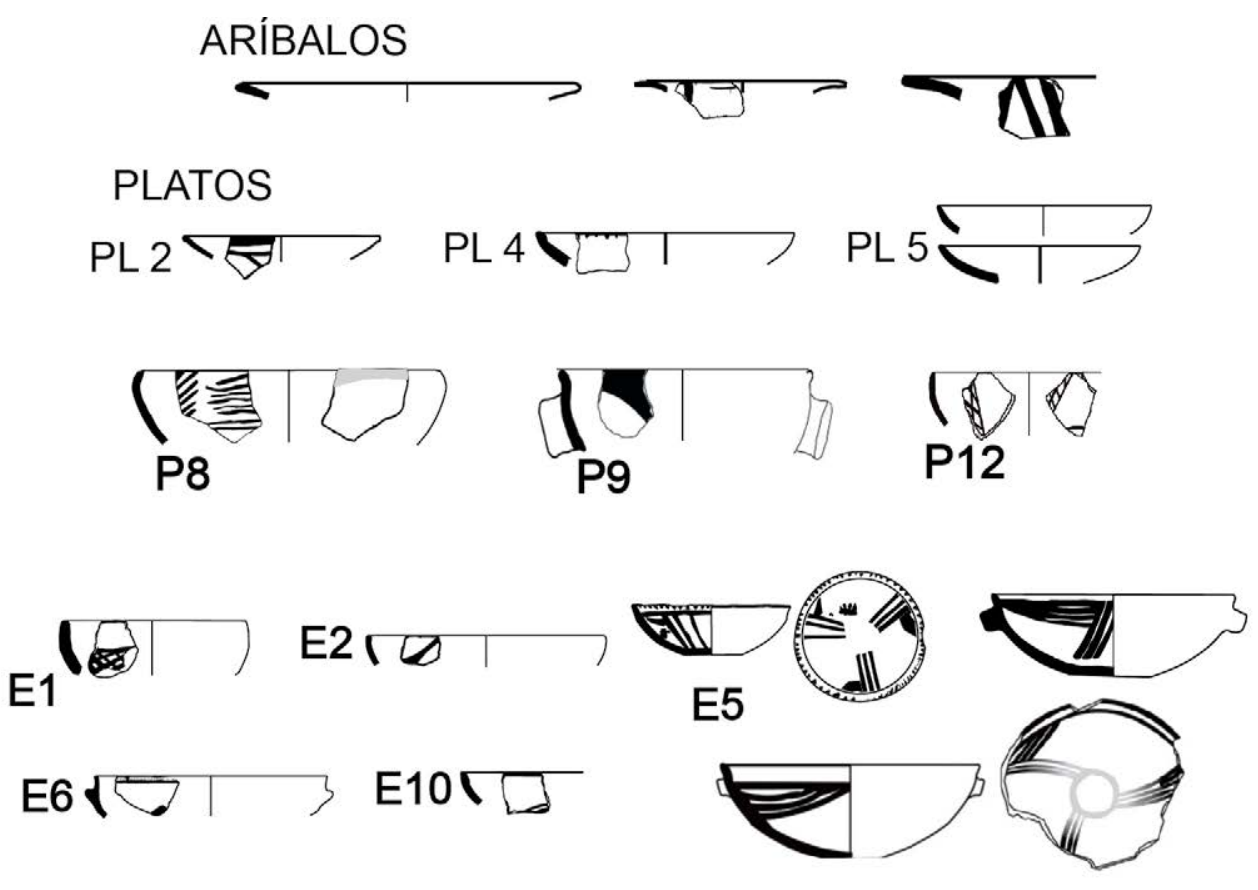

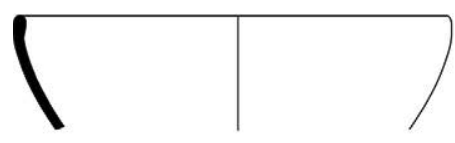

F8
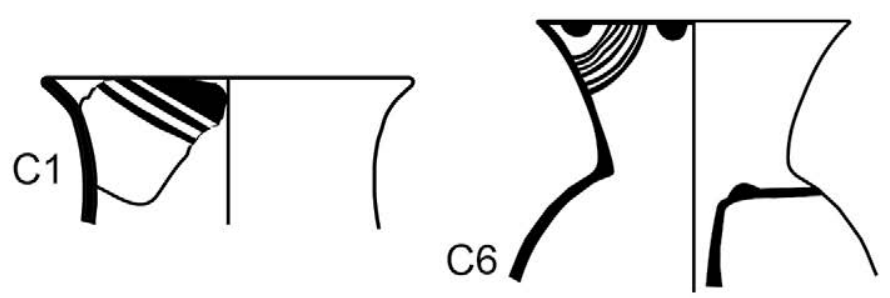

F2
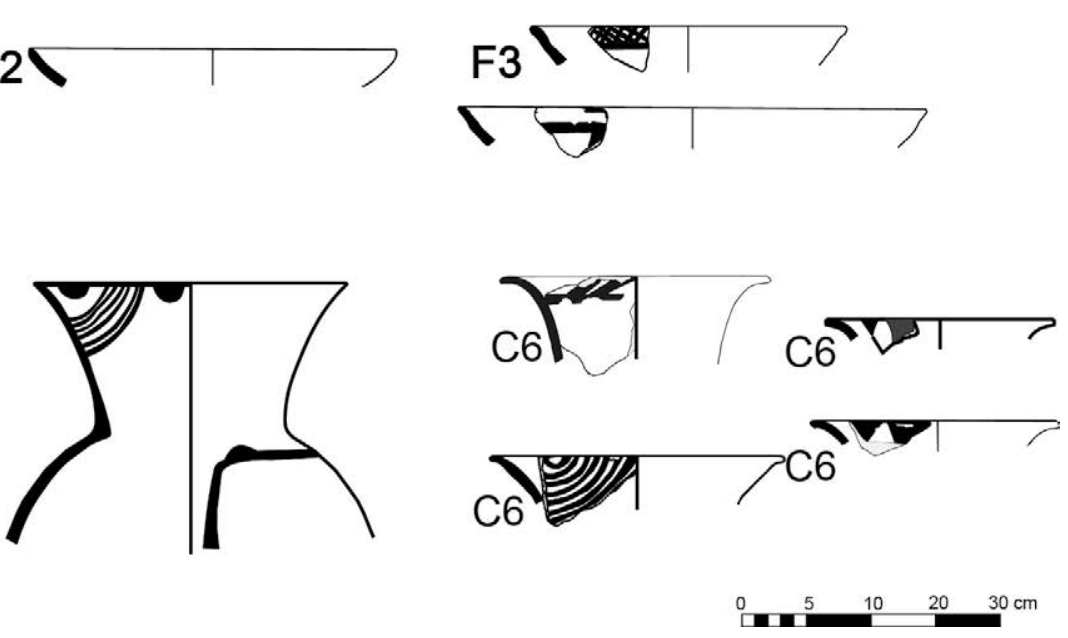

Figura 7. Nuevas formas registradas para la cerámica Humahuaca-Inca (la sigla en cada vasija indica su variedad morfológica).

La decoración corresponde a incisiones profundas punteadas o a grandes incisiones arrastradas dispuestas en el área del cuello y en algunos casos circunscriptas por ángulos incisos formando una guarda horizontal.

Las vasijas ACHI de la muestra analizada $(\mathrm{n}=30: 285)$ incluyen cántaros y ollas (Figura 8), observándose una mayor variedad de formas durante el Incaico, caracterizadas por la presencia de bordes fuertemente evertidos que en algunos casos pueden llegar a ser horizontales y en ocasiones reforzados con una tira al pastillaje. Sólo se ha registrado la continuidad de los cántaros de variedad 5 , si bien las ollas de variedad 11 podrían corresponder a una transformación de la variedad 6 (Figura 8 C5, O6 y O11).

A nivel decorativo (Figura 8), las piezas ACHI del PT se caracterizan por incisiones punteadas irregulares de poca profundidad y arrastradas en sentido vertical $\mathrm{u}$ horizontal. 


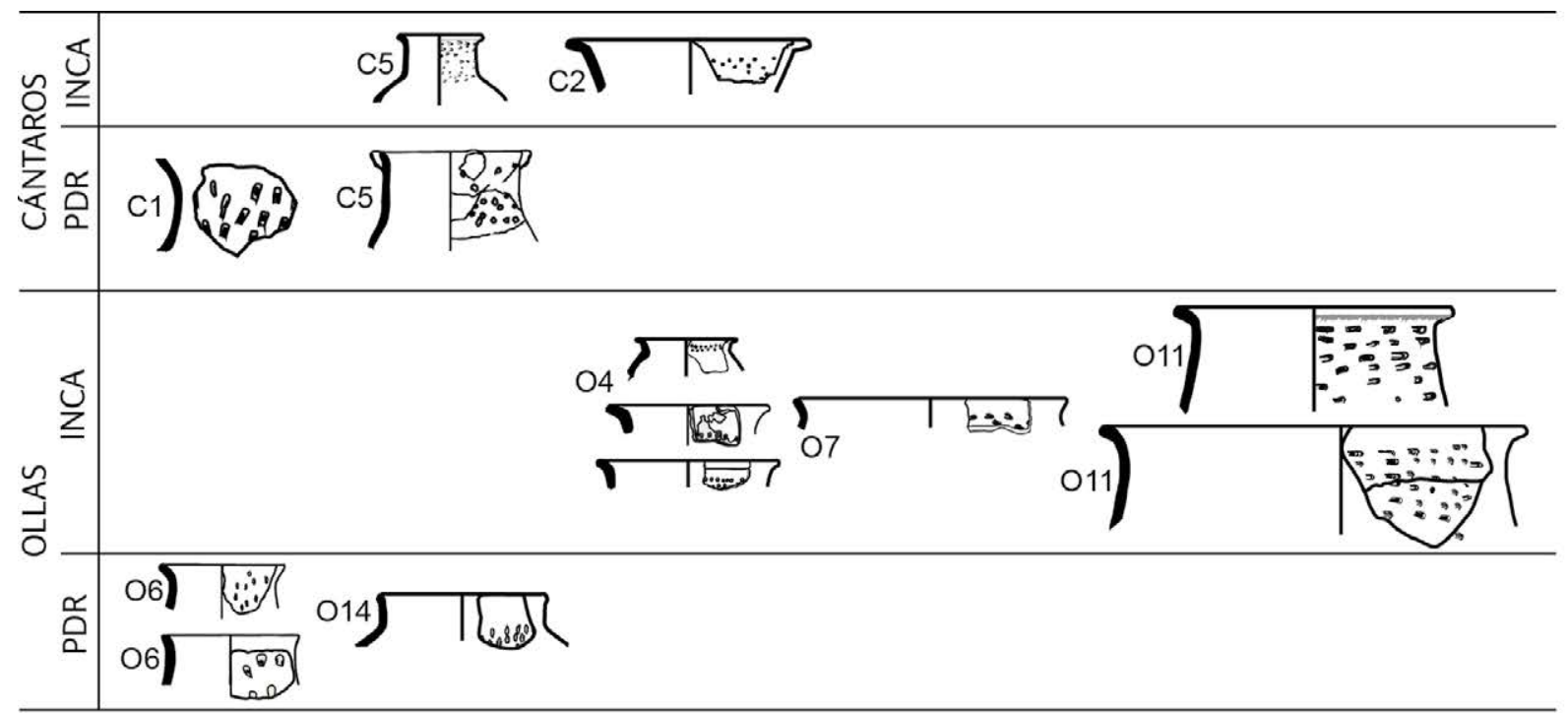

IID

$10 \mathrm{~cm}$

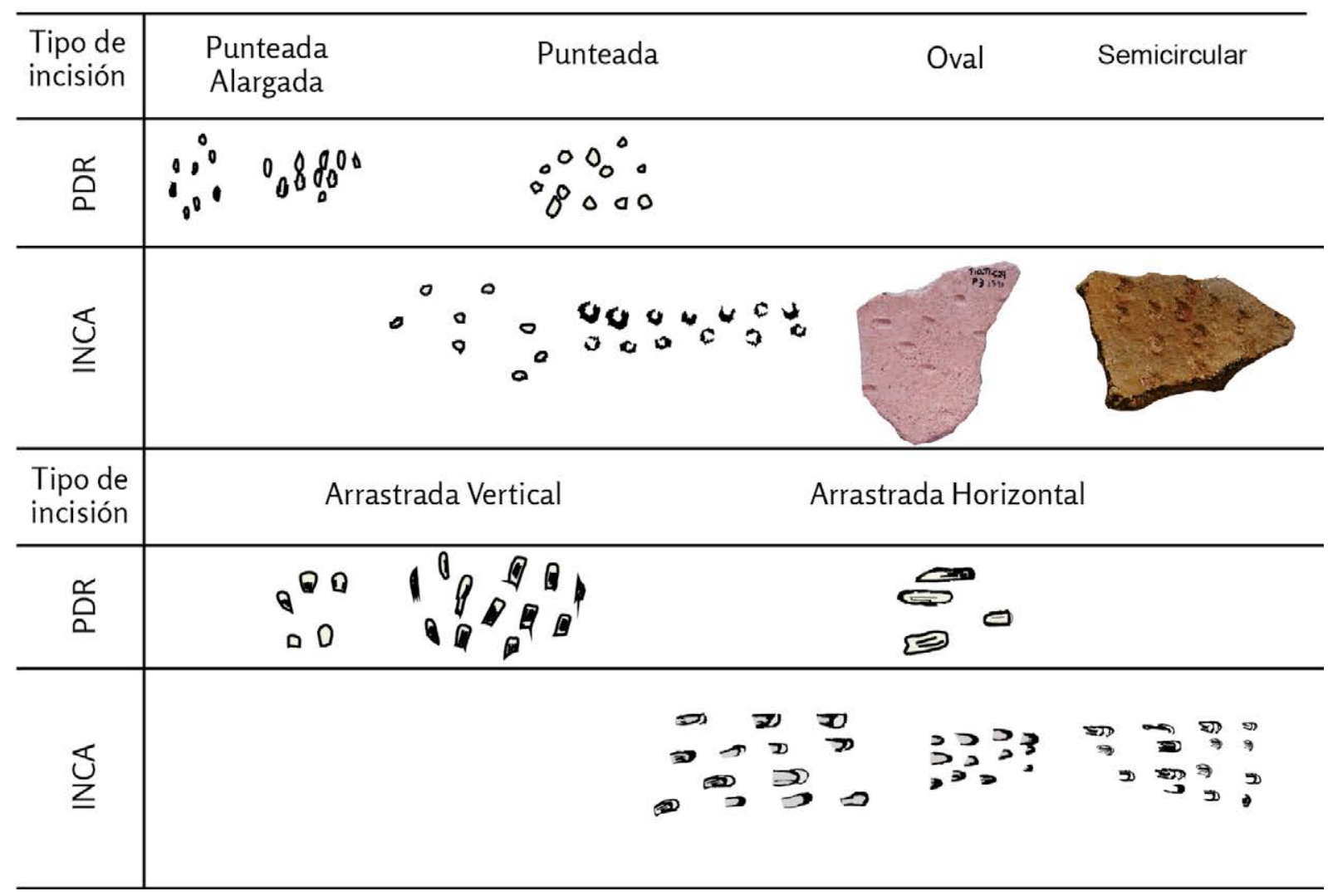

Figura 8. Vasijas Angosto Chico Inciso de los períodos Tardío e Incaico. Arriba: variedades morfológicas identificadas (las siglas junto a las vasijas indican la variedad morfológica); abajo: tipos de incisión registrados. 
Las mismas están dispuestas de forma irregular en el cuello de las vasijas (Regla de Combinación 5). Para momentos incaicos se observó una mayor variedad de incisiones, incluyendo arrastradas grandes, subcirculares, punteadas, y ovales, dispuestas en la mayoría de los casos en hileras (Regla de Combinación 10) y más raramente de forma irregular (Regla 5). Las incisiones sub-circulares fueron registradas en el material de los niveles superiores del Basurero Tum1B2 de Pucara de Volcán (Cremonte y Solís, 1998) y en el material de superficie de Pucara de Perchel y fueron propuestas como un diseño que habría surgido en momentos Incaicos para el estilo ACHI (Scaro, 2009). Los hallazgos del sector centro-sur avalan esta hipótesis de trabajo.

Las vasijas ACHI halladas en El Pobladito confirman la presencia de este estilo en el sector centro-sur de la Quebrada en momentos preincaicos, ya que en los niveles inferiores de los basureros Tum1B1 y Tum1B3 de Pucara de Volcán —fechados en el PT- están ausentes (Cremonte y Solís, 1998). Resulta interesante la variabilidad observada tanto a nivel de las formas como de los elementos decorativos, expresada también en sus pastas, ya que existen diferencias en la naturaleza y proporción de las inclusiones no plásticas que señalan la presencia de vasijas de manufactura local y no local (Cremonte y Larcher, 2015).

La presencia de piezas de producción local y alóctona en los mismos contextos en El Pobladito permite proponer que durante el PT los habitantes del sector centro-sur de Quebrada de Humahuaca tenían vínculos con aquellos de los valles orientales, de donde provenían las vasijas ACHI de manufactura no local. La apropiación del mencionado estilo por los quebradeños indica que tales interacciones habrían sido estrechas.

\section{Pucos Interior Negro Pulido}

En Quebrada de Humahuaca se ha observado la continuidad de los Pucos Interior Negro Pulido desde el Formativo hasta por lo menos el período Incaico (Nielsen, 2007). Si bien se ha propuesto la existencia de variaciones en estas piezas a lo largo del tiempo aún no se han analizado detalladamente.

En el material que se analizó en este trabajo, los Pucos Interior Negro Pulido de momentos preincaicos $(n=9: 14: 285)$ son en todos los casos de perfil simple con borde directo de labio redondeado (puco variedad 6) con el interior negro de poco pulido a pulido y cuyo exterior puede ser ordinario o con engobe rojo alisado. Para el período Incaico $(n=5: 14: 285)$ se observa la continuidad de los pucos de la variedad 6 con las características mencionadas, así como la presencia de la variedad 4, que en el PT sólo agrupa piezas ordinarias y Humahuaca N/R. Los pucos de la variedad 4 se asemejan a los Pucos Bruñidos con una forma sub-elipsoidal. Esta semejanza se ve acentuada por superficies internas y externas muy pulidas.

\section{Vasijas ordinarias y alisadas con engobe}

Son escasas las vasijas de servicio $(n=12: 51: 285)$ que no presentan ninguna decoración o que poseen un engobe rojo alisado; sólo los vasos chatos de variedad 2 y los pucos de la variedad 6 presentan continuidad en los momentos tardíos mientras que en las vasijas restantes observamos cambios a nivel morfológico (Figura 9). El puco de la variedad 13 hallado en El Pobladito forma parte de las vasijas de servicio de paredes rectas divergentes, propuestas como manufacturas características de las poblaciones del sector centro-sur. Si bien la pieza en cuestión no posee la decoración recurrente de una banda horizontal de "reticulado romboidal" su forma resulta sugerente, ya que permite pensar que no sólo la decoración sino también la forma de estas vasijas de servicio participaría activamente en la construcción y transmisión de diversos mensajes. 

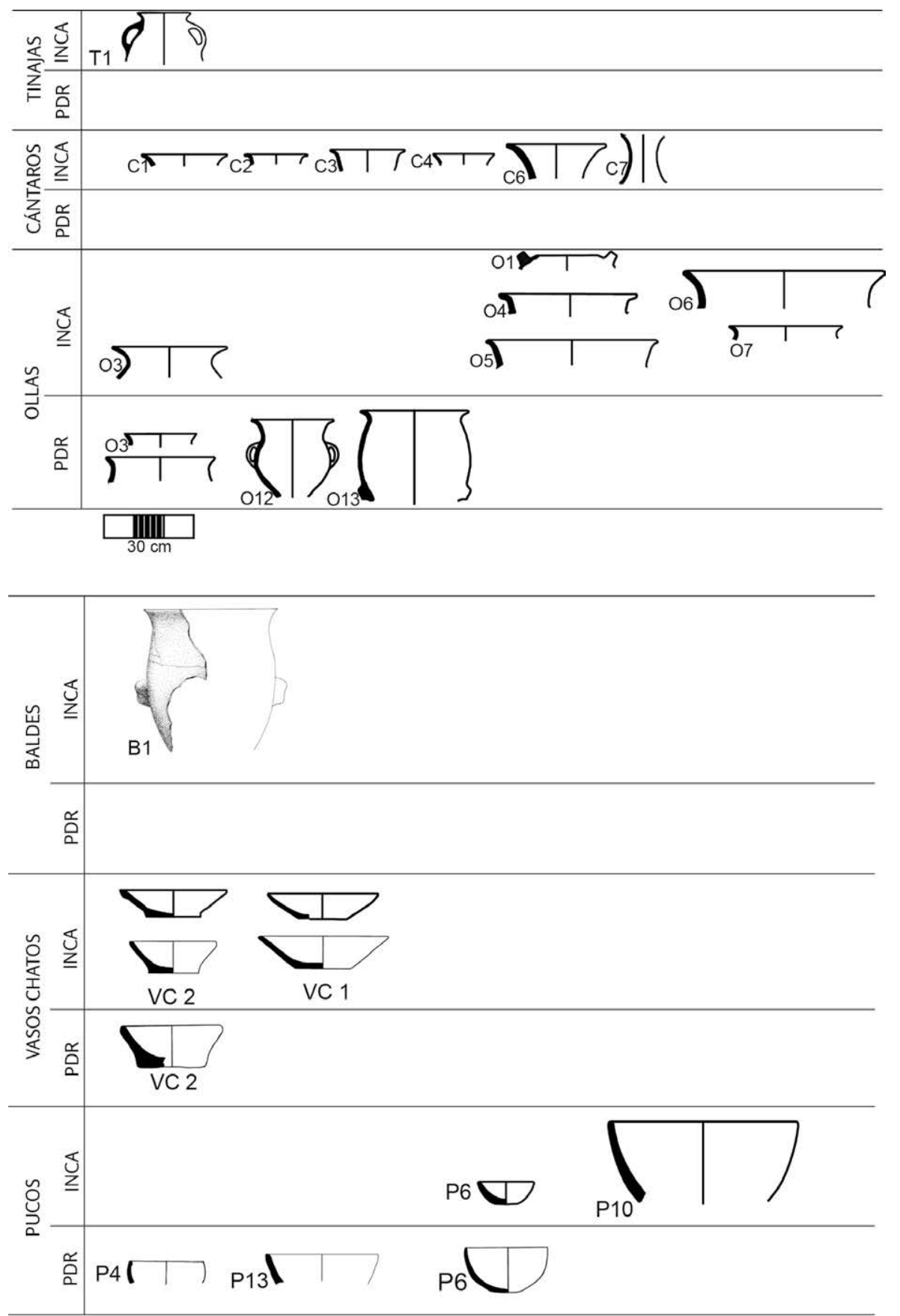

IIIII

Figura 9. Cambios y continuidades en las vasijas ordinarias de los períodos Tardío e Incaico. Arriba: piezas de servicio. Abajo: piezas de cocción-almacenamiento.

Los vasos chatos variedad 2 de momentos prehispánicos tardíos habrían sido utilizados en labores de hilandería, de acuerdo a las huellas dejadas por el huso en el interior de la base. En el caso de un vaso entero hallado en Esquina de Huajra, se recuperó también el tortero, elaborado a partir de un fragmento negro sobre rojo reutilizado.

Las vasijas de cocción/almacenamiento ordinarias son las más numerosas $(\mathrm{n}=39: 51: 285)$ y variadas en cuanto a su forma (Figura 9) y sólo las ollas de cuello hiperboloide (variedad 
3) se mantienen en el período Incaico. Las variedades 12 y 13 de las ollas no habían sido registradas hasta el momento para el sector centro-sur, permitiendo ampliar el repertorio morfológico del sector para el PT.

\section{Pulidos lisos}

Este conjunto $(n=20: 285)$ agrupa fragmentos caracterizados por presentar superficies pulidas de color negro, castaño y rojo, que no pudieron ser asignados a estilos o tipos conocidos. La presencia de piezas de superficies pulidas sin decoración pintada se correlaciona con el aumento de vasijas Humahuaca N/R con ese tratamiento de superficie durante el Incaico. A nivel morfológico, con excepción de la tinaja de variedad 1 , las vasijas pulidas lisas presentan variedades no registradas para momentos anteriores.

El Rosado Pulido Liso se manifiesta como un tipo incaico local recurrente en el sector centro-sur de Quebrada de Humahuaca (Scaro y Cremonte, 2012), registrándose variedad de formas entre las que se destacan el puco variedad 2, la fuente variedad 4 y los aríbalos como innovaciones propias de momentos incaicos. La mayoría de los aríbalos hallados en el sector centro-sur son pulidos lisos, situación que está en concordancia con lo propuesto por Bray (2004) quien observó un aumento de las superficies pulidas sin decoración en los aríbalos hallados en los sitios de la periferia, tendencia opuesta al centro del imperio. La autora vinculó esta diferencia con el interés por parte de la administración incaica de comunicar mensajes diferentes a las poblaciones de las regiones provinciales.

\section{Comparaciones con alfarerías de los distintos sectores de Quebrada de Humahuaca}

Con el fin de identificar variaciones en la alfarería que pudieran estar vinculadas con las identidades locales que se habrían constituido en los distintos sectores de Quebrada de Humahuaca durante el PT, se comparó la cerámica del sector centro-sur con la recuperada en contextos preincaicos de sitios más septentrionales (Figura 1) como Ciénaga Grande (Pérez, 1976; Runcio, 2009, 2010), Pucara de Hornillos (Casanova, 1942a; Robledo, Arenas y Cremonte, 1995; Runcio, 2009, 2010), Pucara de Tilcara (Otero, 2006, 2013; Runcio, 2009, 2010), Pucara de Juella (Cigliano, 1967; Nielsen, Ávalos y Menacho, 1997; Runcio, 2009, 2010), Angosto Chico (Casanova, 1942b; Rivolta, Otero y Seldes, 2010; Runcio, 2009, 2010; Scaro, 2009), Pucara de Perchel (Scaro, 2009), La Huerta (López, 2004; Palma, 1997; Raffino y Palma, 1993; Runcio, 2009, 2010), Los Amarillos (Nielsen, 1997; Runcio, 2009, 2010) y Yacoraite (Runcio, 2009, 2010). Se trabajó a partir de las vasijas ilustradas en las publicaciones mencionadas y discutiendo la adscripción cronológica establecida por los autores para las piezas, ya que en muchos casos se trata de material de colecciones que no tienen control cronológico.

Se consideraron los elementos decorativos pintados identificados para el Humahuaca $\mathrm{N} / \mathrm{R}$, teniendo en cuenta su presencia o ausencia y también su configuración en las vasijas (Tabla 2). En relación con los elementos decorativos definidos para el sector centro-sur, El Pobladito y Pucara de Volcán comparten la mayoría de los mismos, a medida que se avanza hacia el norte la cantidad de elementos compartidos disminuye. Una excepción la constituye Pucara de Tilcara en el sector central de la Quebrada, que comparte siete de los elementos identificados para el sector centro-sur, aunque de acuerdo a lo observado, las configuraciones de los mismos son diferentes.

Los elementos decorativos registrados en los sitios considerados presentan variaciones en su configuración. Las guardas de líneas negras paralelas que aparecen en el 


\begin{tabular}{|c|c|c|c|c|c|c|c|c|c|c|c|c|}
\hline $\begin{array}{l}\text { Elementos } \\
\text { decorativos }\end{array}$ & E.P. & P.deV. & L.S. & C.G. & P.deH. & P.deT. & P.deJ. & P.deP & A.Ch. & L.H. & L.A. & Yac. \\
\hline Línea Negra Sola & $x$ & $x$ & $x$ & $x$ & $x$ & $x$ & $x$ & $x$ & $x$ & $x$ & $x$ & $x$ \\
\hline $\begin{array}{l}\text { Guarda de Líneas } \\
\text { Negras }\end{array}$ & $x$ & $x$ & $x$ & $x$ & $x$ & $x$ & $x$ & $x$ & $x$ & $x$ & $x$ & $x$ \\
\hline Semicírculos & $x$ & $x$ & & $x$ & & $x$ & & $x$ & & $x$ & & \\
\hline Manos o"Alas" & $x$ & $x$ & & $x$ & $x$ & $x$ & $x$ & $x$ & $x$ & & $x$ & \\
\hline Espiral Reticulada & $x$ & $x$ & & & & $x$ & & $x$ & $x$ & & $x$ & $x$ \\
\hline Banda Reticulada & $x$ & $x$ & $x$ & $x$ & $x$ & $x$ & $x$ & $x$ & $x$ & $x$ & $x$ & $x$ \\
\hline $\begin{array}{l}\text { Guarda de } \\
\text { Tríangulos Negros }\end{array}$ & $x$ & $x$ & & $x$ & $x$ & $x$ & & & & & & \\
\hline “Espigado” & $x$ & $x$ & & & & & & & & & & \\
\hline $\begin{array}{l}\text { Líneas Irradiando } \\
\text { desde el Centro }\end{array}$ & $x$ & & & & & & & & & & & \\
\hline
\end{tabular}

Tabla 2. Presencia de elementos decorativos identificados en el sector centro-sur de Quebrada en otros sitios.

Referencias. E.P.: El Pobladito; P.deV.: Pucara de Volcán; C.G.: Ciénaga Grande; P.deH.: Pucara de Hornillos; P.deT.: Pucara de Tilcara; P.deJ.: Pucara de Juella; A.Ch.: Angosto Chico; P.deP.: Pucara de Perchel; L.H.: La Huerta; L.A.: Los Amarillos; Yac.: Yacoraite.

interior de las vasijas de servicio son más complejas en los sitios del sector central y septentrional de la Quebrada, registrándose líneas curvas y asociadas a triángulos negros con espirales en el vértice. En la muestra analizada del sector centro-sur sólo se observan guardas de líneas rectas. Los semicírculos registrados en El Pobladito y en los niveles inferiores de los basureros de Pucara de Volcán aparecen siempre en el borde interno de vasijas cerradas, asociados a una línea negra sobre el labio. En los sitios del sector central también está presente este diseño, aunque en Pucara de Tilcara y Pucara de Perchel los semicírculos ubicados en el borde interno de vasijas de cocción/ almacenamiento pueden presentar el centro pintado de negro o un sólo semicírculo negro, variantes registradas en el sector centro-sur sólo para el período Incaico de acuerdo a lo observado en Huajra y Pucará de Volcán. En un caso de Pucara de Tilcara este elemento decorativo aparece en el borde interno de una vasija de servicio, asociado a guardas de líneas negras dispuestas en forma de cruz.

Las manos o "alas" están presentes en sitios del sector centro-sur y central, y no fueron registradas en la alfarería del sector norte de Quebrada de Humahuaca. Si bien el elemento decorativo es siempre el mismo, un triángulo negro con líneas negras que se extienden desde su base, las configuraciones son diferentes. En Pucara de Volcán y El Pobladito este elemento está presente en vasijas de servicio, asociado a líneas negras o bandas reticuladas, siempre dispuestas de forma circular o espiralada en la parte interna de las vasijas. En Pucara de Tilcara, Angosto Chico y Hornillos las manos aparecen en general con una disposición lineal en el interior de vasijas de servicio y asociada al diseño de "línea recta con líneas cortas oblicuas", elemento ausente en el material del sector centro-sur.

La banda reticulada resultó un elemento decorativo recurrente en los sitios considerados, tanto en el interior de las vasijas de servicio como en el exterior de las vasijas de cocción/ almacenamiento. En el sector centro-sur predomina la banda dispuesta en el borde interno de las vasijas de servicio, siendo más raras las configuraciones de una banda recta en el centro de la pieza, observada en los sitios más septentrionales. En las vasijas de servicio están ausentes las dos bandas reticuladas paralelas ubicadas en el borde interno y las bandas reticuladas con una configuración tripartita, registradas en Pucara de Tilcara y Los Amarillos. En las vasijas de cocción/almacenamiento del sector centrosur es más común la presencia de bandas reticuladas verticales paralelas que se repiten 
alrededor del cuerpo de la vasija en un campo delimitado por líneas, siendo más rara la configuración de bandas cruzadas, común en los sitios más septentrionales. Si bien el reticulado es un diseño recurrente en Quebrada de Humahuaca, se pudo observar que en los sitios del sector medio están elaboradas con un trazo de fino a medio $(<6$ $\mathrm{mm}$ ), mientras que en aquellos del sector centro-sur los trazos son de medios a gruesos (4 a $21 \mathrm{~mm})$.

La guarda de triángulos negros es también un elemento que se repite en diversos sitios del sector centro-sur y central, observándose una misma configuración: dos guardas de triángulos negros dispuestas en vertical y enfrentadas, separadas por una banda reticulada también vertical, ubicadas en el cuerpo superior de las vasijas de cocción/almacenamiento. En los sitios del sector central en ocasiones aparecen también triángulos reticulados configurados de la manera descripta, este tipo de guarda sólo fue registrada en contextos incaicos del sector centro-sur. En el sector central de la Quebrada, la guarda de triángulos negros aparece asociada también a "flechas" y óvalos reticulados, elementos decorativos que están ausentes del repertorio iconográfico del sector centro-sur y que se considera como un elemento que habría aparecido en los últimos momentos del PT, de acuerdo al fechado obtenido en Pucara de Perchel (Scaro y Gheggi, 2011).

El "espigado" sólo aparece en el sector centro-sur en la superficie externa de vasijas de cocción/almacenamiento, asociado a la guarda de triángulos negros o a bandas reticuladas verticales. Este elemento decorativo se presenta como propio del repertorio iconográfico del sector centro-sur de la Quebrada para el PT.

El único elemento decorativo exclusivo de El Pobladito son las líneas irradiando desde el centro, localizado en el interior de un pequeño vaso chato Humahuaca N/R. Se trata de una pieza excepcional por el pequeño tamaño del vaso y el elemento decorativo asociado. Si bien los vasos chatos decorados son escasos en los sitios de Quebrada de Humahuaca, los registrados en Pucara de Perchel y Pucara de Tilcara presentan líneas negras formando guardas o una banda reticulada.

Algunos elementos decorativos propios del sector central y norte de la Quebrada no fueron hallados en el sector centro-sur. Además de "flechas" y óvalos o arriñonados reticulados ya mencionados, están los triángulos negros con espirales en un vértice, las "líneas negras con líneas oblicuas" y las espirales o círculos concéntricos, esta últimas sólo identificadas en el período Incaico en el sector centro-sur. Asimismo, están ausentes o son muy escasos en el sector centro-sur algunos estilos cerámicos recurrentes en el sector medio, como el Juella Polícromo (estilo también ausente en Ciénaga Grande) o los Pucos Poma, ausentes en El Pobladito pero presentes en la colección Gatto de Pucara de Volcán aunque en contextos sin fechados radiocarbónicos. Por otra parte, el engobe rojo fugitivo sólo fue registrado en alfarería del sector centro-sur y en un único tiesto de Ciénaga Grande (Pérez, 1976), esta característica aparece también en algunos tipos de Tastil en la Quebrada del Toro (Cremonte, 2006).

En relación con la manufactura de la alfarería, se ha podido establecer que las vasijas locales de El Pobladito presentan pastas similares a las de Pucara de Volcán, de acuerdo a lo observado en los niveles preincaicos de los basureros Tum1B1 y Tum1B3 (Cremonte, 2006; Cremonte y Larcher, 2015; Cremonte y Solís, 1998). Esta situación manifiesta un mismo modo de hacer alfarero, resultado de decisiones compartidas en cuanto a la selección y tratamiento de materias primas. De esta manera, la alfarería en todos sus aspectos - morfológicos, decorativos y de manufactura- refleja y a la vez refuerza una identidad compartida entre los grupos que ocuparon El Pobladito y Pucara de Volcán durante el PT. En este sentido, la muestra de pastas proveniente de El Pobladito ha permitido identificar un "modo de hacer" para la manufactura de 
las vasijas locales, llevando a establecer que la tradición de manufactura quebradeña estaba bien constituida durante el PT.

\section{Consideraciones finales}

El análisis estilístico de la cerámica de momentos prehispánicos tardíos del sector centro-sur de Quebrada de Humahuaca ha permitido establecer las características morfológicas, iconográficas y de manufactura de las vasijas de cada período considerado. La comparación del estilo Humahuaca N/R de distintos asentamientos de Quebrada de Humahuaca ha permitido detectar recurrencias y también particularidades en este estilo para el período Tardío.

Se plantea la existencia de un estilo Humahuaca N/R regional que pone de manifiesto que los habitantes de los distintos sectores de la Quebrada compartían un lenguaje plástico común. Los mensajes inscritos en la cerámica remitirían a códigos compartidos a nivel regional. A partir del mismo, los habitantes de cada sector de la Quebrada habrían construido identidades particulares, seleccionando ciertos elementos decorativos propios. En este sentido, la presencia de diferencias a nivel de los elementos decorativos y de sus configuraciones registradas entre los sitios analizados, reforzaría la hipótesis del surgimiento de grupos con identidades diferentes en Quebrada de Humahuaca que compartirían un universo de significaciones reflejado en el estilo regional Humahuaca N/R.

Los atributos de la alfarería del sector centro-sur que reflejarían el uso de la materialidad para expresar y negociar una identidad particular incluirían la presencia de la banda reticulada de malla abierta y forma romboidal realizada con trazo grueso, el diseño "espigado" para las vasijas de cocción/almacenamiento y la presencia de engobe rojo fugitivo. Asimismo, Cremonte (2006) ha señalado que existiría una tendencia hacia una proporción más elevada de cuarzo y cuarcitas en las pastas de la alfarería proveniente del sector centro-sur de la Quebrada. A nivel morfológico, la recurrencia de vasijas de servicio con paredes rectas divergentes tanto en el material de El Pobladito como el de los basureros de Volcán y la colección Gatto permite pensar que esta forma particular sería parte también de los elementos propios de la alfarería de la sección centro-sur. En este sentido, los códigos visuales por medio de los cuales se transmitirían mensajes vinculados a la identidad, la memoria y la política no se limitarían a los diseños pintados sino que los mismos abarcarían la vasija de manera integral, considerando también las tradiciones de manufactura y la forma de las vasijas, permitiendo visibilizar dichos aspectos en contextos de comensalidad tanto públicos como privados.

Siguiendo a Lazzari (2005) se considera que los objetos vinculan a las personas con los lugares, construyendo al paisaje de manera dinámica y colectiva. En este sentido, la alfarería local señala un modo de hacer que remite a la selección y empleo de los recursos locales del sector, permitiéndonos pensar en una apropiación del territorio, el cual es incorporado en la materialidad y vinculado directamente con la identidad local.

La presencia de piezas no locales como algunas vasijas ACHI y Pucos Bruñidos daría cuenta de un paisaje que va más allá de lo local mediante las interacciones establecidas con los grupos orientales, evidenciada en la presencia del estilo ACHI y con los de las tierras altas de acuerdo a la presencia de Pucos Bruñidos. La existencia de piezas ACHI de manufactura local y no local en los mismos contextos, tanto públicos como domésticos en el caso de El Pobladito, indica que este estilo de probable origen oriental (debido a su mayor abundancia en esa área) habría sido apropiado por los quebradeños, formando parte de la vajilla cotidiana. Esto podría señalar vínculos de parentesco y de 
interacción social, política y económica con grupos del pedemonte oriental, hipótesis ya propuesta por Fumagalli (2005).

La administración incaica introdujo transformaciones en el sector centro-sur de la Quebrada, sin embargo algunos aspectos de "lo local" vinculados con la identidad y la vida cotidiana permanecieron. Esta continuidad está reflejada en la persistencia de la tradición de manufactura establecida en el PT, así como de algunas formas y decoraciones en el nuevo contexto. En relación con las diferencias identitarias entre las distintas secciones de Quebrada de Humahuaca mencionadas para el PT, se observan algunas particularidades del sector centro-sur durante el Incaico que podrían reflejar el mantenimiento de estas identidades bajo el dominio imperial. Tal es el caso de la ausencia de "pelikes" registrados en Pucara de Tilcara (Otero, 2013), de óvalos y espirales rellenos con líneas paralelas registrados en Pucara de Perchel (Scaro, 2009) y Pucara de Tilcara (Otero, 2013) y el uso del elemento decorativo de manos o "alas" en la superficie externa de vasijas de cocción/almacenamiento registradas en Pucara de Tilcara (Otero, 2013).

Respecto de la presencia de vasijas de manufactura no local en los contextos incaicos del sector centro-sur de la Quebrada, la misma remite a las esferas de interacción en las que este sector estaba inserto bajo la administración estatal. Esto, considerando que los objetos permiten expandir el espacio social compartido, vinculando a los habitantes de la zona con los de otras regiones, como las tierras altas de la Puna jujeña y el sur de Bolivia. De esta manera, el consumo de estas vasijas en eventos públicos como los llevados a cabo en el complejo de "plaza-montículo-cementerio" de Pucara de Volcán podría haber servido para exhibir el poder imperial y a la vez para negociar la sujeción al incario de los habitantes del sector. A su vez, el consumo de esta alfarería en contextos domésticos como la Terraza 1 de Esquina de Huajra habría funcionado como un marcador de estatus para los habitantes de este asentamiento. En este sentido, es posible pensar que la cerámica habría sido un elemento activo en el discurso socioideológico de un grupo de élite en situaciones públicas y privadas.

\section{Agradecimientos}

Para el desarrollo de esta investigación se contó con el financiamiento de Agencia Nacional de Promoción Científica y Tecnológica (ANPCYT PICT0538) y de CONICET (PIP0060). Agradezco la colaboración de Valeria López, Nicolás Lamberti, Lautaro Geronazzo, Martín Basso, José Tolaba y María Tejerina, así como a la Comunidad Aborigen de Tumbaya por el apoyo brindado a las investigaciones, sin el cual no habría sido posible el desarrollo de las mismas. Agradezco los comentarios realizados por Clarisa Otero y Beatriz Cremonte así como las sugerencias brindadas por los evaluadores de este trabajo. 


\section{Q Referencias citadas}

" Balfet, H., Fauvet Berthelot, M. H. y Monzon, S. (1983). Pour la Normalisation de la Déscription des Poteries. Paris: Centre National de la Recherche Scientifique.

» Bennett, W., Bleiler, E. C. y Sommer, F. H. (1948). Northwest Argentine archaeology. Yale University Publications in Anthropology 38. New Haven: Yale University.

» Bray, T. (2004). La alfarería imperial inka: una comparación entre la cerámica estatal del área de Cuzco y la cerámica de las provincias. Chungara. Revista de Antropología Chilena, $36(2), 365-374$.

»Bugliani, M. F. (2008). Consumo y Representación en el Sur de los Valles Calchaquíes (Noroeste Argentino): Los Conjuntos Cerámicos de las Aldeas del Primer Milenio A.D. Oxford: BAR International Series 1774.

» Bugliani, M. F. (2010). Códigos estéticos, expresiones plásticas ymodos de representación en la cerámica del Formativo en Yutopián (Valle del Cajón, Noroeste Argentino). Revista del Museo de Antropología, 3, 21-32.

" Casanova, E. (1942a). El Pucara de Hornillos. Boletín del Museo Nacional de Ciencias Naturales, 249-265.

"Casanova, E. (1942b). El yacimiento arqueológico de Angosto Chico. Relaciones de la Sociedad Argentina de Antropología, III, 73-94.

»Cigliano, E. M. (1967). Investigaciones antropológicas en el yacimiento de Juella (Dep. de Tilcara, Provincia de Jujuy). Revista del Museo de La Plata, 6(34), 123-249.

» Conkey, M. W. y Hastorf, C. A. (Eds.) (1990). The Uses of Style in Archaeology. Cambridge: Cambridge University Press.

»Cremonte, M. B. (2005). Cerámicas arqueológicas y sociedad. En D. Santamaría (Ed.), Jujuy: Arqueología, Historia, Economía y Sociedad (pp. 42-55). Jujuy: Cuadernos del Duende.

»Cremonte, M. B. (2006). El estudio de la cerámica en la reconstrucción de las historias locales. El sur de la Quebrada de Humahuaca (Jujuy, Argentina) durante los Desarrollos Regionales e Incaico. Chungara. Revista de Antropología Chilena, 38(2), 239-247.

»Cremonte, M. B. y Bugliani, M. F. (2009). Pasta, forma e iconografía. Estrategias para el estudio de la cerámica arqueológica. Xama, 19-23, 239-262.

"Cremonte, M. B. y Larcher, N. (2015). Informe petrográfico de una muestra de pastas cerámicas de El Pobladito. Informe IDGYM. Manuscrito inédito.

"Cremonte, M. B. y Scaro, A. (2010). Consumo de vasijas cerámicas en un contexto público tardío del Pucara de Volcán (Dto. Tumbaya, Jujuy, Argentina). Revista do Museu de Arqueologia e Etnologia, 20, 147-161.

»Cremonte, M. B. y Solís, N. (1998). La cerámica del Pucará de Volcán. Variaciones locales y evidencias de interacción. En M. B. Cremonte (Ed.), Los Desarrollos Locales y sus Territorios (pp. 155-178). Jujuy: EdiUnju.

»Cremonte, M. B. y Williams, V. (2007). La Construcción Social del Paisaje durante la Dominación Inka en el Noroeste Argentino. En A. E. Nielsen, M. C. Rivolta, V. Seldes, M. Vazquez y P. Mercolli (Comps.), Procesos Sociales Prehispánicos en el Sur Andino (pp. 207-236). Córdoba: Brujas. 
" D'Altroy, T., Williams, V. y Lorandi, A. (2007). The inkas in the southlands. En R. Burger, C. Morris y R. Mattos (Eds.), Variations in the Expression of Inka Power (pp. 85-133). Washington: Dumbarton Oaks.

»Deambrosis, M. S. y De Lorenzi, M. (1973). La influencia incaica en la Puna y Quebrada de Humahuaca. República Argentina. Revista del Instituto de Antropología, 4, 129-139.

»Fernández Do Rio, S. (2010). Prácticas Locales, Poder Imperial y Control Espacial. Dominio Inca y Relaciones Coloniales en el Sector Medio de la Quebrada de Humahuaca. (Tesis Doctoral Inédita), Universidad de Buenos Aires, Argentina.

» Fumagalli, M. (1998). El Pucará de Volcán, historia ocupacional y patrón de instalación. En M. B. Cremonte (Ed.), Los Desarrollos Locales y sus Territorios (pp. 131-153). Jujuy: EdiUnju.

»Fumagalli, M. (2005). El Sur También Existió: Panorama Arqueológico del Sector Meridional de la Quebrada de Humahuaca y su Borde Oriental. En D. Santamaría (Ed.), Jujuy: Arqueología, Historia, Economía y Sociedad. Jujuy: Cuadernos del Duende.

» Gatto, S. (1946). Exploraciones arqueológicas en el Pucara de Volcán. Revista del Museo de La Plata, IV(18), 5-91.

» González, A. R. y Pérez, J. A. (1966). El Área Andina Meridional. Trabajo presentado en el XXXVI Congreso Internacional de Americanistas. Sevilla, España.

» Hodder, I. (1990). Style as historical quality. En M. W. Conkey y C. A. Hastorf (Eds.), The Uses of Style in Archaeology (pp. 44-51). Cambridge: Cambridge University Press.

» Hyslop, J. (1993). Factors influencing the transmission and distribution of Inka cultural materials throughout Tawantinsuyu. En D. S. Rice (Ed.), Latin American Horizons: A symposium at Dumbarton Oaks, 1986 (pp. 337-356). Washington D.C.: Dumbarton Oaks.

» Jernigan, E. (1986). A Non-hierarchical approach to ceramic decoration analysis: A southwestern example. American Antiquity, 51(1), 3-20.

»Knappett, C. (2008). The neglected networks of material agency: Artefacts, pictures and texts. En C. Knappett y L. Malafouris (Eds.), Material Agency. Towards a NonAnthropocentric Approach (pp. 139-159). Nueva York: Springer.

» Lazzari, M. (2005). The texture of things: Objects, people, and landscape in Northwest Argentina (First Millennium A.D.). En L. Meskell (Ed.), Archaeologies of Materiality (pp. 126-161). Londres: Blackwell.

» Leibowicz, I. (2013). Testimonios de un Adiós. Rituales y Abandono en Juella ante la Conquista Inka de Huamhuaca. Arqueología, 19(1), 153-176.

» López, M. A. (2004). Tecnología cerámica en La Huerta. Quebrada de Humahuaca, Provincia de Jujuy, República Argentina. (Tesis Doctoral inédita), Universidad de Buenos Aires, Argentina.

" Mac Sweeney, N. (2011). Community, Identity and Archaeology. Dynamic Communities at Aphrodisias and Beyesultan. Michigan: University of Michigan Press.

» Madrazo, G. B. (1970). El complejo estilístico “Angosto Chico Inciso”. Etnía, 11, 24-28.

» Madrazo, G. B. y Ottonello, M. (1966). Tipos de instalación prehispánica en la región de la Puna y su Borde. Olavarría: Museo Etnográfico Municipal Dámaso Arce.

» Martínez, J. L. (2010). “Mandó pintar dos aves...”: Relatos orales y representaciones visuales andinas. Chungara. Revista de Antropología Chilena, 42(1), 157-167.

» Martínez, J. L. y Martínez, P. (2013). Narraciones andinas coloniales. Oralidad y visualidad en los Andes. Journal de la Société des Americanistes, 99(2), 41-81. 
》 Miller, D. (2005). Materiality. Durham: Duke University Press.

»Nielsen, A. E. (1997). Tiempo y Cultura Material en la Quebrada de Humahuaca, 700-1650 d.C. Tilcara: Publicaciones del Instituto Interdisciplinario Tilcara.

» Nielsen, A. E. (2001). Evolución social en Quebrada de Humahuaca (AD 700-1536). En E. E. Berberián y A. E. Nielsen (Eds.), Historia Argentina Prehispánica (pp. 171-264). Córdoba: Brujas.

» Nielsen, A. E. (2006). Plazas para los Antepasados: Descentralización y Poder Corporativo en las Formaciones Políticas Preincaicas de los Andes Circumpuneños. Estudios Atacameños, 31, 63-89.

» Nielsen, A. E. (2007). El Período de Desarrollos Regionales en la Quebrada de Humahuaca. Aspectos cronológicos. En V. Williams, B. Ventura, A. Callegari y H. Yacobaccio (Eds.), Sociedades Precolombinas Surandinas (pp. 235-250). Buenos Aires: Ed. Buschi.

» Nielsen, A. E., Ávalos, J. y Menacho, K. (1997). Lejos de la Ruta y sin un Pucara. Cuadernos de la Facultad de Humanidades y Ciencias Sociales (UNJu), 9, 203-220.

» Nielsen, A. E., Hernández Llosas, M. I. y Rivolta, C. (2004). Nuevas Investigaciones Arqueológicas en Juella (Jujuy, Argentina). Estudios Sociales de NOA, 7, 93-116.

» Nielsen, A. E. y Walker W. (1999). Conquista Ritual y Dominación Política en el Tawantinsuyu: El Caso de Los Amarillos (Jujuy, Argentina). En A. Zarankin y F. Acuto (Eds.), Sed Non Satiata (pp. 153-169). Buenos Aires: del Tridente.

» Núñez Regueiro, V. A. (1974). Conceptos instrumentales y marco teórico en relación al desarrollo cultural del Noroeste Argentino. Revista del Instituto de Antropología, 5, 169190.

» Ortiz, M. G. y Delgado, A. (1997). La Cerámica del Pucara de Volcán. Jujuy: EdiUnju.

» Ortiz, M. G. y Delgado, A. (2002). Un lugar en el mundo. Estilo y territorio en Humahuaca. Gaceta Arqueológica Andina, 26, 193-206.

"Otero, C. (2006). Análisis Cerámico del Recinto 2 de la Unidad 1, Sector Corrales del Asentamiento Urbanizado de Tilcara (SJujTil 1-UH 1). (Tesis de Licenciatura inédita), Universidad de Buenos Aires, Argentina.

» Otero, C. (2013). Producción, Usos y Circulación de Bienes en el Pucara de Tilcara (Quebrada de Humahuaca, Jujuy). (Tesis Doctoral inédita), Universidad de Buenos Aires, Argentina.

» Otero, C. y Rivolta, C. (2015). Nuevas interpretaciones para la secuencia de ocupación de Tilcara (Quebrada de Humahuaca, Jujuy). Intersecciones en Antropología, 16, 145-159.

»Ottonello, M. (1994). La cerámica Angosto Chico Inciso en el sitio del Volcán en el sector meridional de la Quebrada de Humahuaca. En M. E. Albeck (Ed.), Taller de Costa a Selva (pp. 329-352). Tilcara: Publicaciones del IIT.

»Palma, J. (1997). Patrones de intercambio de la Quebrada de Humahuaca, Noroeste Argentino. Estudios Atacameños, 14, 121-129.

»Pelissero, N. (1969). Arqueología de la Quebrada de Juella: su integración en la cultura Humahuaca. Jujuy: Dirección Provincial de Cultura.

"Pérez, J. A. (1973). Arqueología de las Culturas Agroalfareras de la Quebrada de Humahuaca (Provincia de Jujuy, República Argentina). América Indígena, 33(3), 667-678.

»Pérez, J. A. (1976). Análisis Cerámico de las Investigaciones Arqueológicas en el Yacimiento de Ciénaga Grande (Departamento Tumbaya, Provincia de Jujuy). (Tesis Doctoral inédita), Universidad Nacional de Córdoba, Argentina. 
» Raffino, R. A. y Alvis, R. (1993). Las “ciudades” Inka en Argentina: Arqueología de La Huerta de Humahuaca. El sistema de poblamiento prehispánico. En R. A. Raffino (Ed.), Inka. Arqueología, Historia y Urbanismo del Altiplano Andino (pp. 37-76). Buenos Aires: Corregidor.

» Raffino, R. A. y Palma, J. (1993). Las “ciudades” Inka en Argentina: Arqueología de La Huerta de Humahuaca. Los artefactos. En R. A. Raffino (Ed.), Inka. Arqueología, Historia y Urbanismo del Altiplano Andino (pp. 93-130). Buenos Aires: Corregidor.

» Reboratti, C. (2003). La Quebrada. Buenos Aires: La Colmena.

» Rice, P. (1987). Pottery Analysis. A sourcebook. Chicago: University of Chicago Press.

» Rivolta, C., Otero, C. y Greco, C. (2017). Reconsidering Isla Occupation. Pottery, Chronology, and Settlement. En A. Scaro, C. Otero y M. B. Cremonte (Eds.), Pre-Inca and Inca Pottery Quebrada de Humahuaca, Argentina (pp. 29-51). Cham: Springer.

» Rivolta, C., Otero, C. y Seldes, V. (2010). Actualización de la problemática del sitio Angosto Chico (Jujuy, Argentina). Arqueología, 16, 87-103.

» Robledo, N. M., Arenas, L. y Cremonte, M. B. (1995). Hornillos: análisis y distribución de cerámicas de superficie. Cuadernos de la Facultad de Humanidades y Ciencias Sociales (UNJu), 5, 189-204.

» Ruiz, M. y Albeck, M. E. (1997). El fenómeno “Pucara” visto desde la Puna Jujeña. Estudios Atacameños, 12, 75-87.

» Runcio, M. A. (2009). Estilos e Identidades: Producción y Consumo de Vasijas Cerámicas en la Quebrada de Humahuaca durante los Períodos Tardío e Inca (900-1536 d.C.). (Tesis Doctoral inédita), Universidad de Buenos Aires, Argentina.

»Runcio, M. A. (2010). Estilos e identidades: los pucos subhemisféricos Negro/Rojo de la Quebrada de Humahuaca durante el Período Tardío (900-1430 d.C.). Comechingonia Virtual, 4(2), 163-210.

»Runcio, M. A. (2012). Producción y consumo de vasijas cerámicas en la Quebrada de Humahuaca (Provincia de Jujuy, Argentina) durante el Período Inka (1430-1536 DC). Boletín del Museo Chileno de Arte Precolombino, 17(1), 61-73.

»Scaro, A. (2009). El Pukara de Perchel (Til 4). Arqueología e Historia de un Lugar Estratégico en la Quebrada de Huamahuaca (Jujuy, Argentina). (Tesis de Licenciatura inédita), Universidad Nacional de Jujuy, Argentina.

»Scaro, A. (2015a). Arqueología de Tumbaya. Paisajes sociales en un sector de la Quebrada de Humahuaca (Jujuy) durante la etapa agroalfarera. (Tesis Doctoral inédita), Universidad de Buenos Aires, Argentina.

»Scaro, A. (2015b). La alfarería de El Pobladito (Tumbaya, Jujuy, Argentina). Una aproximación al Período Intermedio Tardío de Tumbaya a partir del estudio cerámico. Chungara. Revista de Antropología Chilena, 47(3), 455-468.

»Scaro, A. y Cremonte, M. B. (2012). La vajilla de servicio de Esquina de Huajra (Dpto. Tumbaya, Jujuy, Argentina). Alternativas teóricas para interpretar su significado. Revista del Museo de Antropología, 5, 31-44.

»Scaro, A. y Gheggi, M. S. (2011). Entierros de adultos en urna en la Quebrada de Humahuaca. Un caso de estudio del Pucara de Perchel (Dto. Tilcara, Jujuy). Comechingonia, 14, 9-22.

»Scattolin, C. (2007). Estilos como recursos en el Noroeste Argentino. En A. E. Nielsen, C. Rivolta, V. Seldes, M. Vázquez y P. Mercolli (Eds.), Procesos Sociales Prehispánicos en el Sur Andino (pp. 291-321). Córdoba: Brujas. 
"Shanks, M. y Tilley, C. (1987). Re-Constructing Archaeology. Teory and Practice. Cambridge: Cambridge University Press.

"Sica, G. (2008). Tierras Indígenas, Tierras de Españoles en la Quebrada de Humahuaca. Una Historia en Larga Duración. Siglos XVII-XVIII. Trabajo presentado en las XXI Jornadas de Historia Económica. Caseros, Argentina.

» Sica, G. y Sánchez, S. (1996). Pueblos Indígenas de la Quebrada de Humahuaca. En X. Albó, M. I. Arratia, J. Hidalgo, L. Núñez, A. Llagostera, M. I. Remy y B. Revesz (Comps.), La Integración Surandina Cinco Siglos Después (pp. 287-306). Cuzco: Centro Bartolomé de las Casas.

» Skibo, J. M. y Feinman, G. M. (Eds.) (1999). Pottery and People. A Dynamic Interaction. Salt Lake City: University of Utah Press.

» Tarragó, M. (1977). Relaciones Prehispánicas entre San Pedro de Atacama (Norte de Chile) y Regiones Aledañas: La Quebrada de Humahuaca. Estudios Atacameños, 5, 51-64.

" Tarragó, M. (2000). Chakras y Pukara. Desarrollos sociales tardíos. En M. Tarragó (Ed.), Nueva Historia Argentina (pp. 257-299). Barcelona: Sudamericana.

» Tarragó, M. y Albeck, M. E. (1997). Fechados Radiocarbónicos para el Sector Medio de la Quebrada de Humahuaca. Avances en Arqueología, 3, 101-116.

» Tarragó, M., González, L. R., Ávalos, G. y Lamamí, M. (2010). Oro de los Señores. La Tumba 11 de la Isla de Tilcara (Jujuy, Noroeste Argentino). Boletín del Museo Chileno de Arte Precolombino, 15(2), 47-63.

»Troncoso, A. (2005). Hacia una semiótica del arte rupestre de la cuenca superior del río Aconcagua, Chile Central. Chungara. Revista de Antropología Chilena, 37(1), 21-35.

»Williams, V. (2000). El Imperio Inka en la provincia de Catamarca. Intersecciones en Antropología, 1, 55-78.

»Williams, V. y D’Altroy, T. (1998). El sur del Tawantinsuyu: un dominio selectivamente intensivo. Tawantinsuyu, 5, 170-178.

»Zaburlín, M. A. (2009). Historia de Ocupación del Pucara de Tilcara: Jujuy, Argentina. Intersecciones en Antropología, 10, 89-103.

»Zaburlín, M. A. (2012). La cerámica tricolor de la Puna Jujeña: Variabilidad de los elementos decorativos con vírgulas y puntos blancos. Arqueología, 18, 131-152. 